\title{
DESCUBRIMIENTOS Y EXHIBICIÓN DE MOMIAS GUANCHES EN LA PRIMERA MITAD DEL SIGLO XIX. MUSEOS EUROPEOS (MONTPELLIER, GÖTTINGEN, SAN PETESBURGO, GINEBRA) Y GABINETES CIENTIIFICOS INSULARES DE SAVIÑÓN Y MEGLIORINI
}

\author{
Alfredo Mederos Martín \\ Universidad Autónoma de Madrid \\ Gabriel Escribano Cobo \\ Universidad de La Laguna
}

\begin{abstract}
RESUMEN
La exhibición de dos momias en el Gabinete de Historia Natural de París despertó el interés de diversas expediciones científicas que hicieron escala en Tenerife en la primera mitad del siglo XIX. La de Nicolas Baudin en 1800 coincidió con el descubrimiento de una cueva con momias en El Sauzal y tres acabaron en los museos de las universidades de Montpellier y Göttingen y otra en el gabinete de Saviñón. Otra momia fue entregada a la expedición rusa de von Krusenstern de 1803, actualmente en el museo de San Petesburgo. Una nueva cueva con momias se descubrió ca. 1815 en Tacoronte y pasaron al gabinete científico de Megliorini, mientras que otra se localizó en Valleseco, Santa Cruz, hacia 1823, y fue vendida en el Puerto de la Cruz a un comerciante suizo para el museo de Ginebra.
\end{abstract}

Palabras ClaVe: momias, guanches, siglo xix, coleccionismo de antigüedades.

DISCOVERIES AND EXHIBITION OF GUANCHE MUMMIES IN THE FIRST HALF OF THE

$19^{\text {th }}$ CENTURY. EUROPEAN MUSEUMS (MONTPELLIER, GÖTTINGEN, SAINT PETESBURG, GENEVA) AND SAVIÑÓN AND MEGLIORINI INSULAR SCIENTIFIC CABINETS

\begin{abstract}
The exhibition of two mummies in the Natural History cabinet in Paris aroused the interest of various scientific expeditions that made a stopover in Tenerife in the first half of the 19th century. Nicolas Baudin's expedition in 1800 coincided with the discovery of a cave with mummies in El Sauzal and three ended up in the university museums of Montpellier and Göttingen and one in the cabinet of Saviñón. Another mummy was given to von Krusenstern's Russian expedition of 1803, currently in the museum of Saint Petersburg. A new cave with mummies was discovered ca. 1815 in Tacoronte, which ended up in the scientific cabinet of Megliorini. Another mummy located in Valleseco, Santa Cruz, around 1823, was sold in Puerto de la Cruz to a Swiss merchant for the Geneva museum.
\end{abstract}

KEYWORDs: mummies, guanche, nineteenth century, illustration, antique collecting. 


\section{LAS MOMIAS DE EL SAUZAL EN EL GABINETE DE HISTORIA NATURAL DE DOMINGO SAVIÑÓN EN LA LAGUNA}

El 28 de octubre de 1800, el coronel José de Betancourt y Castro Molina le comentó al tercer vizconde del Buen Paso que cuando residía con su hermana Catalina de Betancourt, casada en 1790 con el capitán Antonio Monteverde y Rivas Ponte y Molina, en su hacienda de El Sauzal', se descubrió «una cueva sepulcral de guanches [...] ha llevado varios curiosos a su observación. Entre ellos el vicecomisario de Francia [Louis] Gros, don Domingo y don Tomás Saviñón, quienes han adquirido algunas piezas del uso de los guanches, como una aguja, otro hueso a la manera de anzuelo de pescador y algunos cadáveres o momias con las envueltas o pieles en las que se han conservado».

El lugar es descrito con cierto detalle, «La cueva está bañada del aire por dos aberturas o puertas, hallándose en ella porción de cadáveres, pero sumergidos bajo una mole inmensa de polvo. Su situación es en lo alto de una montaña muy escarpada. Por una de las puertas es casi inaccesible; por la otra siempre hay peligro que vencer, pero los que dan noticia han entrado en ella con el auxilio de una escalera $»^{2}$.

Debe tratarse de la cueva que describe, sin haberla visitado, Bory de SaintVincent ${ }^{3}$, de muy difícil acceso y distancia a unos $13,9 \mathrm{~km}$ entre La Laguna y El Sauzal, pues la ubica «a una legua y media o dos de La Laguna [11 km $144 \mathrm{~m}$ ], que es la que normalmente se enseña a los viajeros. Está situada en la ladera de una montańa cortada casi a pico, y solo se puede ascender a ella con muchos esfuerzos y con ayuda de varias escalas».

Creemos que corresponde a las cuevas situadas en el tracto superior del barranco de la Negra de El Sauzal. Esta zona de difícil acceso, a la que se llega por el camino que desciende al puertito de El Sauzal, tiene varias cuevas de habitación junto al borde del barranco interconectadas ${ }^{4}$ y por encima de ellas se sitúan otras dos actualmente no accesibles, que antiguamente se podría acceder descendiendo desde la parte superior del acantilado pero en la actualidad, debido a la construcción de un gran chalet hasta el mismo borde, no es posible alcanzarlas, siendo la mejor opción desde arriba con una escalera.

${ }^{1}$ Primo de la Guerra, J. (1976 [1800-1807]): Diario I 1800-1807. L de la Rosa Olivera (ed.). Madrid-Tenerife, p. 56; Peraza de Ayala, J. (1929): «Historia de la Casa de Monteverde IX». Revista de Historia Canaria, 22, p. 181.

2 Primo de la Guerra, J., opus cit., n. 1, p. 56.

3 Bory de Saint-Vincent, J.B.G.M. (1988 [1803]): Ensayo sobre las Islas Afortunadas y la antigua Atlántida o compendio de la Historia General del Archipiélago Canario. La Orotava-Tenerife, p. 47.

${ }^{4}$ Mederos, A. y Escribano, G. (2007): Prehistoria de la Comarca de Acentejo. El menceyato de Tacoronte. Madrid, pp. 306-307, 332-333. 


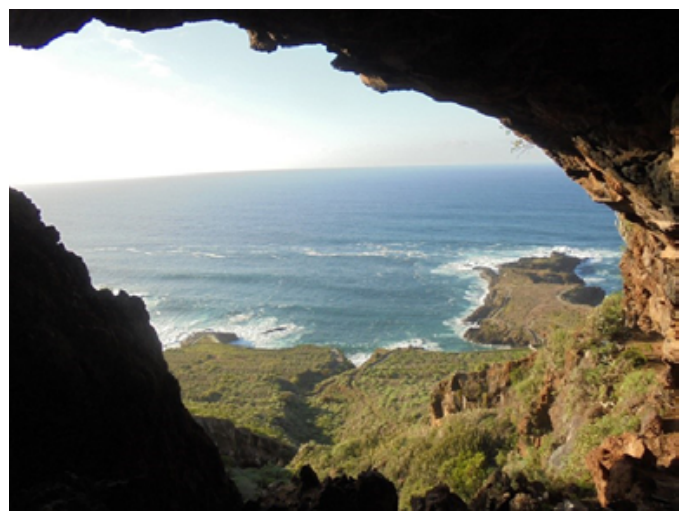

Fig. 1a. Vista desde las cuevas del barranco de la Negra de la desembocadura y el puertito de El Sauzal.

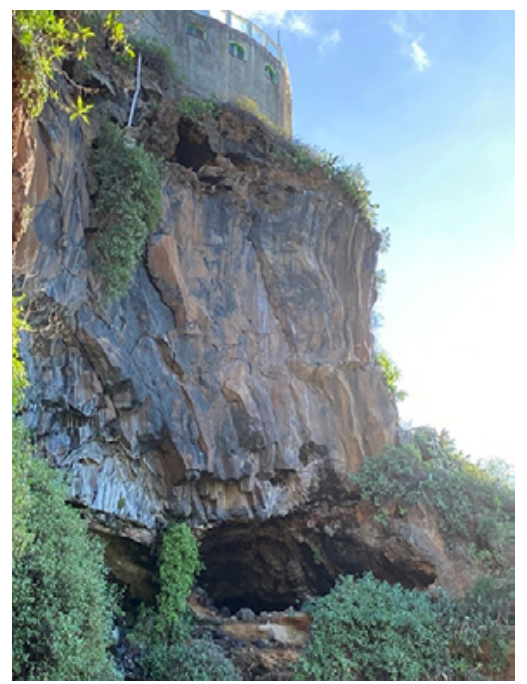

Fig. 1b. Cuevas funerarias del barranco de la Negra de las que proceden las momias de El Sauzal, de la cueva superior una momia infantil.

De la cueva más pequeña y próxima al chalet se extrajo una momia infantil ${ }^{5}$, un niño de 2 meses, atribuida inicialmente a una cueva de El Sauzal ${ }^{6}$ y después a la «punta volcánica que se adentra en el mar» ${ }^{7}$, que debe referirse al Puertito de El Sauzal, el cual se domina desde estas cuevas y junto al cual desemboca el barranco de La Negra. Fue localizada en 1969 por cuatro aficionados en la cota de 175 m.s.n.m., quienes finalmente la acabaron entregando en 1974 al Museo Arqueológico de Tenerife, indicando su procedencia de esta cueva ${ }^{8}$ (figs. 1a-1c).

Pocos días después, a inicios de noviembre de 1800 , tenemos la primera mención a la presencia de una momia en un gabinete de Historia Natural en Tenerife, pues el ilustrador de la expedición científica de Baudin que había llegado a Santa Cruz de Tenerife el 2 de noviembre, Jacques Gérard Milbert ${ }^{9}$ indica: que «Fuimos,

5 Delgado Miranda, com. pers.

${ }^{6}$ Diego Cuscoy, L. (1976): "Glosa a un fragmento de los 'Apuntes' de Don José de Anchieta y Alarcón. (Necrópolis y momias)». Anuario de Estudios Atlánticos, 22, p. 239.

7 Rodríguez Martín, C. (1995): «Una historia de las momias guanches». I Congreso Internacional de Estudios sobre Momias (Puerto de la Cruz, 1992). I, La Laguna, p. 162, fig. 4; Notman, D.N.H. (1995): «Paleoradiology of the guanches of the Canary Islands». I Congreso Internacional de Estudios sobre Momias (Puerto de la Cruz, Tenerife, 1992). I, La Laguna, p. 100.

${ }^{8}$ Mederos, A. y Escribano, G., opus cit., n. ${ }^{\circ}$ 4, p. 219 fot.; Martín Oval, com. pers.

9 Milbert, J.G. 1996 [1812]): Viaje Pintoresco a la Isla de Tenerife. M. Hernández González y J.A. Delgado (eds.). A través del tiempo, 15, La Laguna-La Orotava, pp. 46-47. 


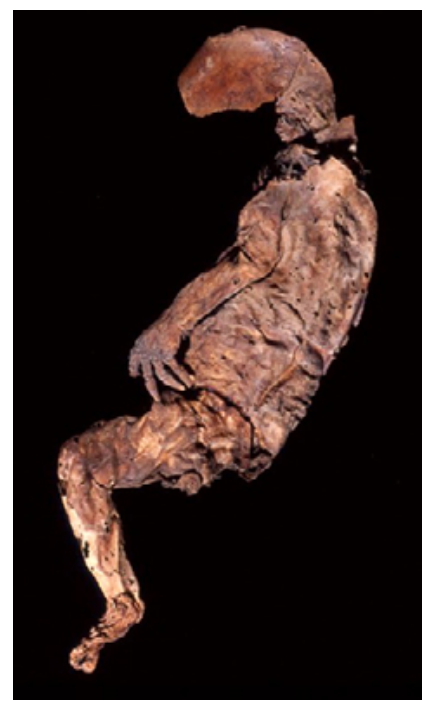

Fig. 1c. Momia infantil de dos meses de El Sauzal. Museo de la Naturaleza y Arqueología de Tenerife.

pues, a la casa del doctor [Domingo] Saviñón [...]. M. Saviñon nos enseñó detalladamente su gabinete de historia natural, donde no solamente había ordenado simétricamente los objetos y curiosidades del país, sino también los de regiones lejanas. Entre los primeros observé una momia guanche perfectamente conservada", que debía proceder de la cueva de El Sauzal descubierta una o dos semanas antes.

Este primer gabinete científico del que tenemos constancia fue de un hijo de Tomás Saviñón y Martínez de Miranda, abogado del Cabildo y regidor perpetuo de Tenerife y de su segunda mujer, Jerónima Nicolasa Yánez y Barrios ${ }^{10}$. Procedía de una familia genovesa liberal (Savignone) asentada en Tenerife desde la llegada de su abuelo, el genovés Nicolás Saviñón.

Domingo Saviñón nació en La Laguna el 31 de julio de 1769, siendo el segundo de tres hermanos, después del abogado Antonio Saviñón, nacido en 1768, que residía en Madrid ${ }^{11}$ y fue nombrado en 1803 diputado por Tenerife en la corte. Domingo heredó de su tío, Carlos Yanes, dinero que le sirvió para pagar sus estudios en medicina en Sevilla, además de una buena colección de libros de leyes y medicina. Ejerció como médico durante unos años en Madrid hasta que regresó a Tenerife en $1796^{12}$. Su hermano menor, Tomás Saviñón, nació el 5 de marzo de 1772, intentó estudiar leyes en la península, pero por problemas médicos regresó

\footnotetext{
10 Primo de la Guerra, J., opus cit., n. ${ }^{\circ}$ 1, p. 79.

11 Primo de la Guerra, J., opus cit., n. ${ }^{\circ} 1$, p. 80.

12 Primo de la Guerra, J., opus cit., n. ${ }^{\circ} 1$, p. 79.
} 
a Tenerife, dedicándose a preparar un gabinete de Historia Natural pues «se aplicó a la lectura de la historia natural [...]. Aprendió a hacer la disección y preparar los pájaros y otros animales que se conservan en los gabinetes»" ${ }^{13}$.

Domingo y Tomás Saviñón marcharon a París, vía Burdeos, el 12 de enero de $1802^{14}$. Varios meses después, primero regresó Tomás el 27 de junio, también vía Burdeos $^{15}$, mientras Domingo lo hizo el 20 octubre de $1802^{16}$. En París adquirió diverso instrumental científico para su gabinete, «son excelentes: se compraron en París, y fue el célebre [abate René Just] Haüy quien los seleccionó» ${ }^{17}$.

Ambos eran dos de los más claros afrancesados de la burguesía lagunera, con regular trato "con los cónsules de Francia, adquirieron retratos de los generales más celebres de la República y estampas de las modas de París. Imitaban sus trajes y maneras, hablaban el idioma y se les veía comúnmente en compañía de algún francés. Su casa ha sido el punto de reunión de la juventud de La Laguna, de los aficionados a la música y gentes que piensan a lo moderno» ${ }^{18}$. No obstante, después de su estancia en París en 1802, Tomás «vuelve menos partidario de los franceses de lo que se manifestaba antes de su viaje» ${ }^{19}$, probablemente por la evolución política del país después de la Revolución de 1789, con el golpe de Estado de Napoleón el 18 de noviembre de 1799 y su proclamación como Primer Cónsul vitalicio.

El 29 de octubre de 1815 Domingo Saviñón fue visitado por el naturalista Adelbert von Chamisso ${ }^{20}$, dentro de la expedición al mando de Otto von Kotzebue, al comienzo de la segunda circunnavegación del globo terráqueo por la flota rusa. La expedición fue financiada por el conde Nikolai Romanzoff y permaneció en la isla hasta el 1 de noviembre.

Al reabrirse la Universidad de San Fernando de La Laguna en 1817, por los esfuerzos del marqués de Villanueva del Prado y de Pedro Bencomo, cuyo hermano, el arzobispo Cristóbal Bencomo, era el confesor de Fernando VII, se incorporó Domingo Saviñón entre sus profesores, como cated rático de Física Experimental ${ }^{21}$. Falleció soltero, con 69 años, el 8 de agosto de 1838, poco años después que su hermano Tomás, que también murió soltero con 60 años el 20 de mayo de 1832 .

Según señala Berthelot, que había llegado a Tenerife en 1820, «Saviñón había estudiado Medicina en Europa. Una larga estancia en París le había puesto en contacto con relevantes personalidades de la ciencia. En su casa yo tenía reservada una habitación, donde de vez en cuando iba a descansar de mis excursiones

13 Primo de la Guerra, J., opus cit., n. ${ }^{\circ} 1$, p. 79.

${ }_{14}$ Primo de la Guerra, J., opus cit., n. ${ }^{\circ} 1$, p. 79.

15 Primo de la Guerra, J., opus cit., n. ${ }^{\circ} 1$, p. 119.

16 Primo de la Guerra, J., opus cit., n. ${ }^{\circ} 1$, p. 133.

17 Berthelot, S. (1980 [1839]): Primera estancia en Tenerife (1820-1830). Tenerife, p. 52.

${ }^{18}$ Primo de la Guerra, J., opus cit., n. ${ }^{\circ}$ 1, p. 80.

19 Primo de la Guerra, J., opus cit., n. ${ }^{\circ} 1$, p. 119.

${ }^{20}$ Chamisso, A. von (1993 [1836]): Viaje alrededor del mundo con la expedición de exploraciones Romanzov durante los años 1815-1818. M. Hernández González y J.A. Delgado (eds.). A través del tiempo, 9. La Orotava-La Laguna, p. 140.

${ }^{21}$ Berthelot, S., opus cit., n. ${ }^{\circ}$ 17, p. 49. 
botánicas. Su gabinete, sus instrumentos, sus mapas, su biblioteca compuesta por los mejores libros antiguos y modernos, estaban a mi disposición. El afecto con el que el querido doctor me ha distinguido, no se entibió jamás. La última carta que escribió fue para mí» ${ }^{22}$.

\section{EL TRASLADO DE MOMIAS DE EL SAUZAL AL MUSEO DE MONTPELLIER}

Hasta la invasión napoleónica en 1808 y la incorporación de España a la guerra de la quinta coalición de Austria y Gran Bretaña contra Francia, los contactos comerciales y escalas de expediciones científicas francesas continuaron llegando a las Islas Canarias y en particular a la isla de Tenerife.

Antes de la firma de la paz de Amiens entre Francia y Gran Bretaña en marzo de 1802, el 18 de octubre de 1800 partieron del puerto de Le Havre dos barcos, Le Géographe y Le Naturaliste, al mando de Nicolas Thomas Baudin en una expedición científica y naturalista hacia el océano Pacífico o mares del sur cuyo objetivo último era cartografiar la costa de Australia. Ambos barcos hicieron una escala de 11 días en el puerto de Santa Cruz de Tenerife entre el 2 y 13 de noviembre de $1800^{23}$. Entre los científicos que viajaban había gran interés por conseguir momias completas o fragmentos de momias. La razón era que entre 1772-1776 habían llegado dos momias de Tenerife al Musée National d'Histoire Naturelle de París, donde al menos una estuvo expuesta poco después ${ }^{24}$.

Jean-Baptiste Bory de Saint-Vincent, un joven naturalista con apenas 22 años, que obtuvo la plaza de zoólogo en la expedición en la corbeta Le Naturaliste, abandonando el ejército donde estaba sirviendo ${ }^{25}$, nos informa que "Todas las personas de la expedición se procuraron fragmentos de las momias [...]. Mr. [Pierre Marie Auguste] Broussonet, tuvo la bondad de darme una entera [...]. Las momias guanches son bastante imperfectas [...]. Parece que no las vaciaban todas, sus intestinos quedaban muchas veces en el cuerpo, y en ciertas momias no se ve costura ó hendidura que denote que se haya tratado de extraer alguna cosa de las cavidades del pecho, del bajo vientre ó del cráneo [...] tienen, sin embargo, un olor bastante

22 Berthelot, S. (1980 [1883]): Recuerdos y Epistolario (1820-1880). L. Diego Cuscoy (ed.). La Laguna, p. 18.

${ }_{23}$ Milbert, J.G. (1996 [1812]): Viaje Pintoresco a la Isla de Tenerife. M. Hernández González y J.A. Delgado (eds.). A través del tiempo, 15. La Laguna-La Orotava, pp. 21-23 y 73.

${ }^{24}$ Daubenton, L.J.M. (1782): Encyclopédie Méthodique: Histoire Naturelle des Animaux. I. Paris, p. 86; Mederos, A. y Escribano, G. (2020): «El inicio del coleccionismo ilustrado de momias guanches durante el siglo XviII. Barranco de Erques y acantilado de Martiánez (Tenerife, Islas Canarias)». Revista de Historia Canaria, 202, pp. 84-85.

${ }^{25}$ Bory de SAInt-Vincent, J.B.G.M. (1994 [1804]): Viaje a las cuatro principales islas de los mares de África, durante los años nueve y diez de la República (1801 y 1802). M. Hernández González y J.A. Delgado (eds.). A través del tiempo, 11. Ediciones J.A.D.L. Tenerife-La Orotava, p. 65. 


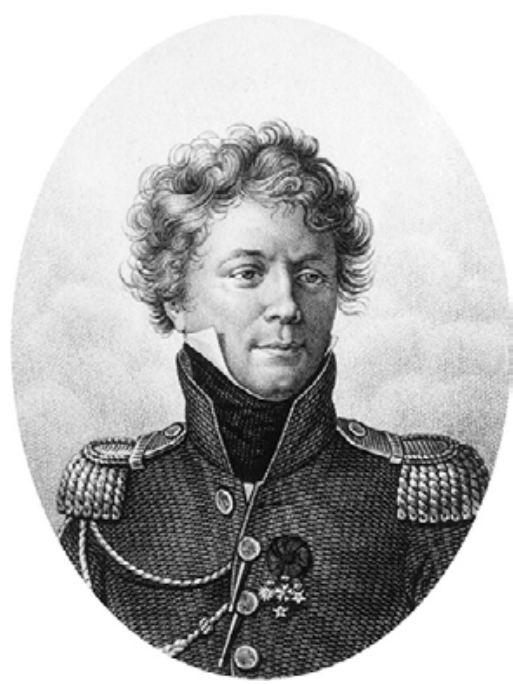

Fig. 2a. Jean-Baptiste Bory de Saint-Vincent, zoólogo en la expedición de la corbeta Le Naturaliste que hizo escala en 1800. Grabado por Ambroise Tardieu en 1810.

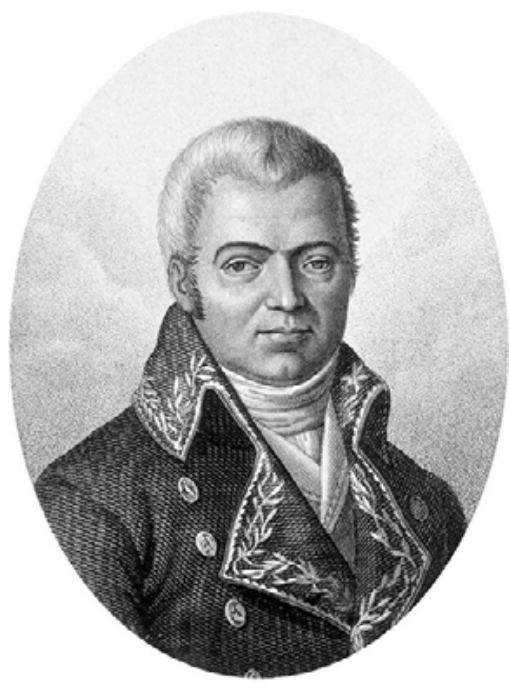

Fig. 2b. Pierre Marie Auguste Broussonet, biólogo y cónsul de Francia en Tenerife. Grabado por Ambroise Tardieu en 1810.

agradable y aromático» ${ }^{26}$. Esta momia parece que se la devolvió a Broussonet, «Bory Saint-Vincent tuvo en 1802 [1800] una momia perfecta, que le sirvió para sus estudios, y que luego devolvió a la persona que se la había dado; dicha momia pasó de manos de Broussonnet a Inglaterra, y ahora seguro que se halla en alguna colección privada ${ }^{27}$ (figs. 2a-2b).

Mas detalles aporta en su texto dedicado a las islas africanas donde parece claro que pudo ver varios ejemplares, «En las pieles de una momia completa, que obtuve gracias a los cuidados de M. Broussonet, encontré que se les había dejado el pelo, vuelto hacia adentro». «Estas momias, tal y como se encuentran hoy en día, son ligeras, secas; varias están perfectamente conservadas y tiene el cabello y la barba; con frecuencia les faltan las uñas [...]. En algunas no se encuentra ninguna huella de incisión; en otras, se ve la cicatriz de una abertura bastante grande en el costado [...] los guanches utilizaban el jugo de euforbia [...]. He visto trozos completos de esa planta en el pecho de una momia en la que, sin embargo, no había ninguna incisión. Me han asegurado que también se han encontrado hojas muy bien conservadas, que se han reconocido como hojas de laurel [...] los brazos de los hombres

26 Bory de Saint-Vincent, J.B.G.M., opus cit., n. ${ }^{\circ} 3$, p. 81.

27 Ṕ́got-Ogier, E. (2009 [1869]): Las Islas Afortunadas o Archipiélago de las Canarias. II. J.J. Vega (ed.). Cabildo de Gran Canaria. Madrid-Las Palmas, pp. 240-241. 
se extendían a lo largo del tronco y las manos de las mujeres, normalmente, se cruzaban por delante de la parte inferior del vientre ${ }^{28}$. Las identificaciones de plantas como la euforbia y del laurel debe habérselas proporcionado Auguste Broussonnet.

Pierre Broussonet le propuso «ir á la Laguna, y visitar una caverna sepulcral de los guanches, pero me quedé para poner orden en mis colecciones ${ }^{29}$. Más datos los proporciona otro visitante de la isla, aunque tampoco fue personalmente, "partieron de Santa Cruz para visitar unas cuevas situadas a poca distancia de La Laguna. Estas cuevas, situadas en el borde del mar, eran el lugar de sepultura de los antiguos guanches ${ }^{30}$. Su presencia en la costa próxima a La Laguna sugiere que la cueva visitada es la misma del descubrimiento de momias en 1800 en El Sauzal.

Su interés por la población aborigen de las islas no era sólo de un coleccionista, sino que en su obra incluye una recopilación de las palabras y topónimos aborígenes conservados e incluso presenta una lámina de útiles aborígenes procedentes de la colección Bernardo Cologan ${ }^{31}$. «Mr. Cologan, Hijo [...] hablaba perfectamente el francés, habitaba de ordinario en la Orotava. Era sobrino de aquel respetable Mr. Cologan que recibió también á los sabios Pingre, de Borda y Labillardiere [1771-1772] [...] nos hablaron con entusiasmo de nuestra revolución de la que eran muy partidarios $\aleph^{32}$. Bernardo Cologan le proporcionó una descripción de la entonces reciente erupción del volcán de Chahorra el 9 de junio de 1798, al que se había desplazado para verlo muy pocos días después, el 18 de junio de $1789^{33}$, y le entregó un grabado con la erupción del volcán a Milbert ${ }^{34}$.

El trabajo de Bory de Saint-Vincent presenta el primer intento de reivindicación del pueblo guanche desde una visión romántica, como supervivientes de la Atlántida: «Parecen los restos de un pueblo que, después de haber sido destruido o dispersado por un acontecimiento que le arrebató casi todos sus conocimientos, se reunió de nuevo para volver a vivir en sociedad ${ }^{35}$.

Sin embargo, por un enfrentamiento con Baudin, el jefe de la expedición, Bory de Saint-Vincent abandonó el barco en la isla Mauricio, entonces denominada por los franceses Île-de-France, y no continuó explorando la isla volcánica de Reunión, que había sido renombrada como île Bonaparte, hasta que regresó a Francia el 11 de julio de 1802 .

La persona que le había proporcionado la momia, el Dr. Auguste Broussonnet, al habérsele prohibido ejercer como doctor en Francia por su vinculación política con los girondinos, había conseguido un puesto de vicecónsul francés en

${ }^{28}$ Bory de Saint-Vincent, J.B.G.M., opus cit., n. ${ }^{\circ}$ 3, pp. 44, n. ${ }^{\circ}$ 3, 46.

29 Bory de Saint-Vincent, J.B.G.M., opus cit., n. ${ }^{\circ} 25$, p. 90.

${ }^{30}$ Milbert, J.G., opus cit., n. ${ }^{\circ}$ 23, p. 56.

31 Bory de Saint-Vincent, J.B.G.M., opus cit., n. ${ }^{\circ}$ 3, p. 54, lám. 2; Bory de Saint-VinCENT, J.B.G.M., opus cit., n. ${ }^{\circ} 25$, p. 107.

32 Bory de Saint-Vincent, J.B.G.M., opus cit., n. ${ }^{\circ} 25$, p. 89.

33 Bory de Saint-Vincent, J.B.G.M., opus cit., n. ${ }^{\circ}$ 3, pp. 73, 168-171, 169 lám.

${ }^{34}$ Milbert, J.G., opus cit., n. ${ }^{\circ}$ 23, p. 40.

${ }^{35}$ Bory de Saint-Vincent, J.B.G.M., opus cit., n. ${ }^{\circ}$ 3, p. 73. 
Mogador desde el 15 de mayo de 1797. Sin embargo, una epidemia de peste en el invierno de 1799-1800 causó la muerte a 6000 de sus 8000 habitantes, pudiendo escaparse en una barca con su familia que después de 36 horas de travesía alcanzó la isla de Lanzarote ${ }^{36}$. Fue nombrado cónsul o comisario de relaciones comerciales en las Islas Canarias el 1 de mayo de $1800^{37}$. Residía en Santa Cruz de Tenerife y durante los veranos, para evitar el calor en el puerto, trasladaba su residencia en una casa en el entorno de La Laguna, en el camino de San Diego, propiedad del marqués de El Sauzal, donde ya es mencionado por Primo de la Guerra ${ }^{38}$ desde el 15 de julio de 1800. Estaba preparando una obra sobre Plantas raras de las Islas Canarias ${ }^{39}$, por lo que en ocasiones este autor no menciona algunas plantas: «En el herbario de M. Broussonet he visto muchas plantas que faltan en mis noticias, pero he creído que no debería hablar de ellas ${ }^{40}$. Cesó en su cargo el 15 de octubre de 1802, sustituido por el vicecónsul Louis Gros, regresando a Francia con su familia, vía Inglaterra, en abril de $1803^{41}$.

Además de la momia completa que le entregó a Bory de Saint-Vincent, el profesor de dibujo de la Escuela de Minas de París, Jacques Gérard Milbert, que navegaba en la corbeta Le Géographe, obtuvo otra momia completa. «Interesado por llevar a mi patria una momia guanche, me proporcionaron una que me proponía dejar en depósito en Île-de-France. Era de una mujer joven. Aunque un poco alterados, los rasgos todavía eran regulares. Las manos estaban bien conservadas, pequeñas, bien hechas; le faltaban cuatro uñas, dos en la mano derecha y otras dos en la izquierda; en los pies, sólo faltaba una en el derecho; los cabellos y las pestańas estaban admirablemente conservados. Contento con esta posesión, no pensé en la dificultad de conservar semejante objeto en una larga travesía. Al principio, coloqué la momia en mi camarote, en una de las repisas situadas por encima de mi cama, pero el calor y la humedad del navío la ablandaron, descomponiendo la preparación, y engendraron allí tal cantidad de insectos que resolví lanzarla al mar» ${ }^{42}$. Probablemente pensaba depositarla en algún museo de puerto Napoleón en Île-de-France ${ }^{43}$, actual capital de la isla Mauricio, en el océano Índico, hasta que fue conquistada por los británicos en 1810, recuperando su antiguo nombre (fig. 3).

Esta momia, probablemente también procedente de la cueva recientemente descubierta en la costa de El Sauzal, se la debió regalar o bien el cónsul francés Auguste Broussonnet o bien Domingo Saviñón y Yáñez (vide infra), «al que había

${ }^{36}$ Ruiz Álvarez, A. (1965): «Apuntes para una biografía del doctor Augusto Broussonet (1761-1807)». Anuario de Estudios Atlánticos, 11, pp. 142-143.

37 Ruiz Álvarez, A. (1960-61): «La isla de La Palma en 1802: informe del cónsul francés Augusto Broussonet a Talleyrand». Revista de Historia Canaria, 26 (129-130), p. 102.

${ }^{38}$ Primo de la Guerra, J., opus cit., n. ${ }^{\circ}$ 1, pp. 46 y 121.

39 Bory de Saint-Vincent, J.B.G.M., opus cit., n. ${ }^{\circ}$ 25, p. 90.

${ }^{40}$ Bory de Saint-Vincent, J.B.G.M., opus cit., n. ${ }^{\circ}$ 3, p. 207.

41 Primo de la Guerra, J., opus cit., n. ${ }^{\circ} 1$, p. 174.

${ }_{42}$ Milbert, J.G., opus cit., n. ${ }^{\circ} 23$, pp. 56-57.

${ }^{43}$ Milbert, J.G., opus cit., n. ${ }^{\circ} 23$, p. 83. 


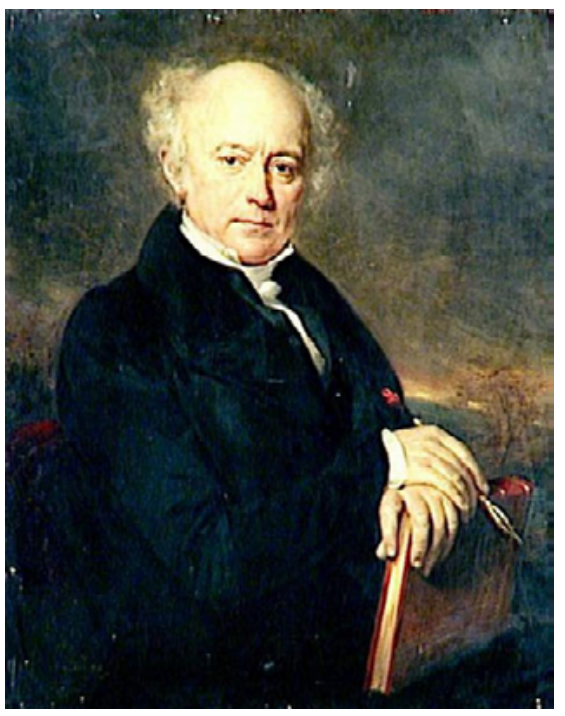

Fig. 3. Jacques Gérard Milbert, dibujante de la expedición Baudin en 1800, por Jean Sébastien Rouillard (1831).

visto varias veces a borde nuestro navío» en cuya vivienda en La Laguna llegó a pernoctar ${ }^{44}$. También habían sido visitados por Bory de Saint-Vincent ${ }^{45}$, quien indica que Domingo Saviñón, «médico distinguido»" ${ }^{46}$,se dedicaba á la historia natural».

Por otra parte, François Péron, quien resalta lo bien que había sido recibido por «nuestros valientes aliados» ${ }^{47}$, como responsable de las investigaciones antropológicas y naturalistas en la expedición de Baudin de 1800, como miembro de la tripulación de Le Géographe, menciona en su Inventaire général de tous les objets relatifs à l'histoire de l'homme que también se llevó de Tenerife un brazo momificado.

Más preciso sobre el origen de este brazo momificado es el segundo oficial de Le Naturaliste, Pierre Bertrand Milius, quien asumió el mando del barco al morir Baudin el 16 de septiembre de 1803. "Se encuentran a menudo momias de guanches en grutas [...]. Los que vimos iban envueltos en una especie de vestido de cuero ceñido con una correa. Nos dividimos una de esas reliquias y a cada uno de

${ }^{44}$ Milbert, J.G., opus cit., n. ${ }^{\circ}$ 23, pp. 46 y 53.

45 Bory de Saint-Vincent, J.B.G.M., opus cit., n. ${ }^{\circ} 25$, pp. 93-94.

${ }^{46}$ Milbert, J.G., opus cit., n. ${ }^{\circ}$ 23, p. 46.

47 Péron, F. y Freycinet, L. de (1996 [1807-16]): Viaje de descubrimientos a las Tierras Australes hecho por orden del gobierno, en las corbetas Le Geographe y Le Naturaliste y la goleta Le Casuarina, durante los años 1800, 1801, 1802, 1803 y 1804. M. Hernández González y J.A. Delgado (eds.). A través del tiempo, 15, La Laguna-La Orotava, p. 116. 
nosotros le tocó un pie, una mano, una pierna o un brazo ${ }^{48}$, lo que parece sugerir que recibieron otra momia casi completa y fue troceada entre varios miembros relevantes de la expedición.

Dos años después, en 1802, se produjo un donativo por Auguste Broussonnet de 2 momias a la universidad de Montpellier, su ciudad de nacimiento. Poco después se incorporó en 1803 a una cátedra de botánica y a la dirección del Jardín de las Plantas de Montpellier antes de su prematuro fallecimiento en 1807 , con apenas 46 años, que le impidió publicar ${ }^{49}$ su monografía sobre la flora de Canarias. Un cráneo de una de estas dos momias, una mujer, es descrito por Joseph Marie Dubreuil $^{50}$, profesor de Anatomía de la Universidad de Montpellier.

Las dos momias se encuentran actualmente en el Conservatoire d'Anatomie de la Faculté de Médecine de Montpellier, donde tienen como fecha de entrada el 4 de junio de $1806^{51}$.

También Broussonnet envió dos cráneos a S.J. Brugmans de Leiden, a través del gobernador de Ciudad del Cabo H. Lichtenstein el 31 de enero de 1803, cráneos guanches «fáciles de encontrar en Tenerife" ${ }^{52}$.

\section{LA MOMIA DE LA UNIVERSIDAD DE GÖTTINGEN}

El médico alemán y uno de los fundadores de la antropología física, Johann Friedrich Blumenbach, doctorado en 1775 en la Universidad de Gotinga (Göttingen), de la que fue nombrado profesor ordinario - catedrático- en 1778 , poseía al menos desde 1802 una momia guanche ${ }^{53}$, concretamente una mujer adulta madura que conservaba sus órganos internos.

La momia le llegó inicialmente al naturalista Sir Joseph Banks, presidente de la Royal Society entre 1778-1820 y miembro de la Society of Antiquaries, residente en el Soho de Londres, quien escribió a Blumenbach el 26 de noviembre de

${ }^{48}$ Milius, P.B. 2000 [1800-04]): Viaje a las tierras australes. Descripción de las Islas Canarias, en B. Pico et al. (eds.): Viajeros franceses a las Islas Canarias. Repertorio bio-bibliográfico y selección de textos. La Laguna-Tenerife, p. 221.

${ }^{49}$ Milbert, J.G., opus cit., n. ${ }^{\circ} 23$, p. 82.

50 Dubreuil, J.M. (1837): «Études anatomiques de têtes ayant appartenu à des individus de races humaines diverses». Comptes rendus hebdomadaires des séances de l'Académie des Sciences, 4 (16), pp. 575-576.

51 Ducourau, C. (2016): «Les restes humains au conservatoire d'anatomie de la faculté de médecine de Montpellier». En N. Timbart, H. Guichard y A. Froment (eds.): Archives de l'humanité: les restes humains patrimonialisés. Techne, 44, pp. 46, 49, n. ${ }^{\circ} 21$.

${ }^{52}$ Heiningen, T.W. van (2010): The correspondence of Sebald Justinus Brugmans (17631819), The Hague, p. 121, n. ${ }^{\circ} 200$.

53 Blumenbach, J.F. (1802): «Eine Guanchen-Mumie von Tenerife. Aus einem Briefe des Hn. Baronet Banks vom 26 Nov. 1801». Magazin für den neuesten Zustand der Naturkunde mit Rücksicht auf die dazu gehörigen Hülfswissenschaften, III (4), pp. 723; BlumenBaCH, J.F. (1790-1808): Decas quinta collectionis suae craniorum diversarum gentium illustrata. V. Gottingae, pp. 7-8. 


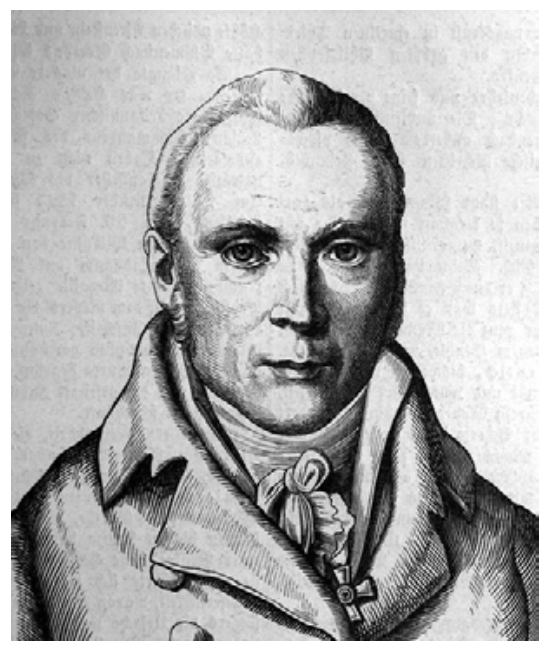

Fig. 4a. Johann Friedrich Blumenbach, profesor de antropología en la Universidad de Göttingen, grabado por Hugo Bükner (1854). National Portait Gallery, London.

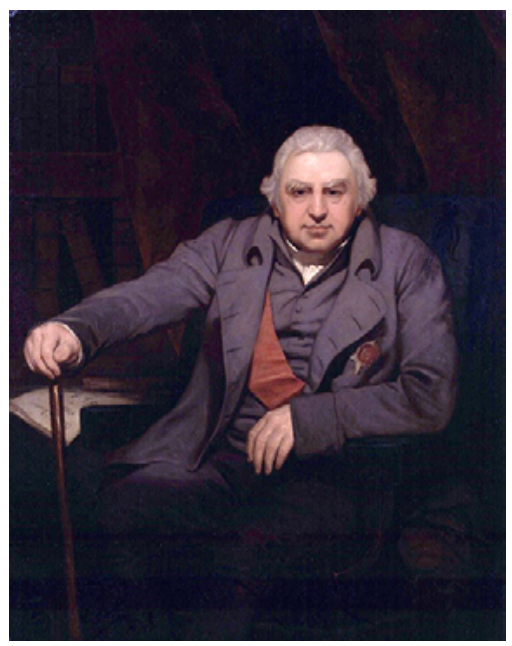

Fig. 4b. Sir Joseph Banks, presidente de la Royal Society de Londres, por Thomas Phillips (1810).

National Portait Gallery, London.

1801 indicándole que «he recibido por último de Tenerife la momia de uno de los Guanches o habitantes aborígenes de las Islas Canarias la cual yo pienso es una curiosidad aceptable para su colección antropológica, está completa y muy perfecta [...] yo se la enviaré si me menciona una persona en Hamburgo a la cual yo la puedo enviar» ${ }^{54}$ (figs. 4a-4b).

El origen de esta momia creemos que quizás sea la que Bory de Saint-Vincent le devolvió a Broussonnet, por su antigua amistad con Joseph Banks cuando residió en Londres entre 1780-1784, pues poco después de acceder a la presidencia de la Royal Society lo nombró miembro en $1781^{55}$. Puesto que sabemos que Bory de Saint-Vincent se marchó de Tenerife el 13 de noviembre de 1800, esta momia pudo enviarse pocos meses después a Inglaterra ${ }^{56}$ donde al menos ya se encontraba en noviembre de 1801 .

La oferta fue excelentemente recibida por Blumenbach que le respondió el 20 de diciembre mostrándole su interés por recibir «esa preciosa momia Guanche, ninguna de las cuales, hasta lo que yo sé, ha sido hasta hora vista en Alemania", sugiriéndole como receptor del envío en «mi dirección en Hamburgo al cuidado de

${ }^{54}$ KLatt, N. (ed.) (2015): The Correspondance of Johann Friedrich Blumenbach. VI. 18011805. Letters 1360-1787. Frank William Peter Dougherty. Revised, Augmented and Edited. Göttingen, p. 111, carta n. ${ }^{\circ} 1442$.

55 Ruiz Álvarez, A., opus cit., n. ${ }^{\circ}$ 36, p. 134.

56 Ṕ́got-Ogier, E., opus cit., n. ${ }^{\circ}$ 27, pp. 240-241. 


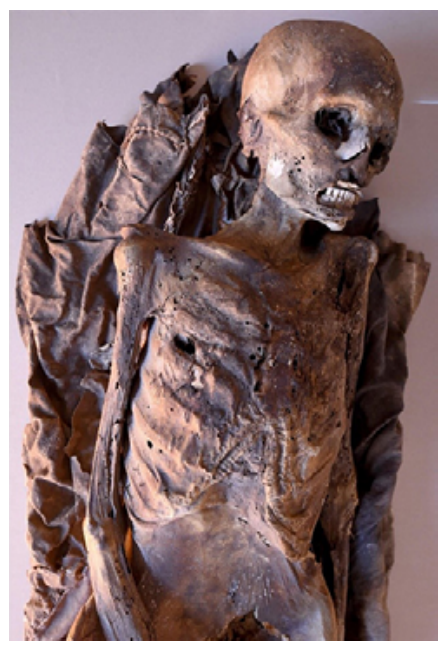

Fig. 5a. Momia de mujer en el Johann Friedrich Blumenbach Institut für Zoologie und Anthropologie de la Universidad de Göttingen.

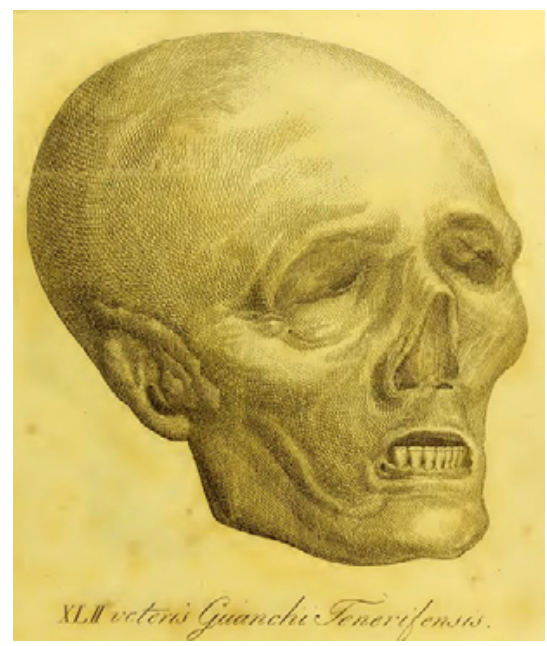

5b. Detalle de la cabeza de la momia (Blumenbach, 1790-1808/5: lám. 42).

Joseph Hirsch Gerson, un antiguo discípulo mío quien me la enviará de la forma más segura y rápida», quien se había doctorado en Gotinga en $1801^{57}$.

La momia salió de Londres el 23 de febrero de 1802, según le informó Banks al día siguiente, enviada por Georg August von Best junto otros paquetes para el duque de Cambridge, señalando también que «Los dientes de la mandíbula inferior están completos» ${ }^{5}$. La momia llegó a Gotinga el 21 de marzo de $1802^{59}$ y es mencionada como la "Dama de Tenerife» en una carta del 14 de marzo ${ }^{60}$. Meses después, el 22 de junio, Blumenbach le comentó a Banks que «Yo estoy todavía ocupado con las investigaciones sobre la preciosa momia de Tenerife» ${ }^{61}$.

Esta momia se conserva actualmente en la colección de antropología física del Johann Friedrich Blumenbach Institut für Zoologie und Anthropologie de la Universidad de Göttingen ${ }^{62}$ y ha sido objeto de un reciente estudio en el hospital de Hildesheim, antes de su exhibición en la exposición en febrero de 2016 en el Roemerund Pelizaeus-Museum de Hildesheim, Alemania (figs. 5a-5b).

${ }^{57}$ Klatt, N. (ed.), opus cit., n. ${ }^{\circ} 54$, pp. 126, carta n. ${ }^{\circ} 1454,127$, n. ${ }^{\circ} 2$.

${ }^{58}$ Klatt, N. (ed.), opus cit., n. ${ }^{\circ}$ 54, p. 142, carta n. ${ }^{\circ} 1462$.

59 KLatt, N. (ed.), opus cit., n. ${ }^{\circ}$ 54, pp. 151, 153, n. ${ }^{\circ} 45$, carta n. ${ }^{\circ} 1467$.

${ }^{60}$ KLatT, N. (ed.), opus cit., n. ${ }^{\circ}$ 54, p. 153, carta n. ${ }^{\circ} 1468$.

${ }^{61}$ Klatt, N. (ed.), opus cit., n. ${ }^{\circ}$ 54, p. 204, carta n. ${ }^{\circ} 1506$.

${ }^{62}$ Beuermann, G.; Hunger, U. y Hische, M. (eds.) (1987): 250 Jahre Georg-AugustUniversität Göttingen. Katalog zur Ausstellung im Auditorium 19. Mai-12. Juli 1987. Georg-AugustUniversität. Göttingen, pp. 109-110. 


\section{LA MOMIA DEL MUSEO DE SAN PETESBURGO}

Otro médico que hizo escala en Tenerife fue el barón (freiherr) prusiano Georg Heinrich von Langsdorff (Grigori Ivanovitch Langsdorff), formado en la Universidad de Göttingen, que fue el médico y naturalista en la gran expedición rusa al mando del capitán de navío Adam Johann von Krusenstern (Iván Fiódorovich Kruzenshtern), nacido en Estonia, de familia de origen alemán, que circunnavegó la tierra entre 1803 y agosto de 1806 y redactó en alemán el relato del viaje. La expedición contó con dos barcos, Nadezhda (Esperanza) al mando de Krusenstern y el Nevá, incorporándose Langsdorff a la expedición en Copenhagen después de un primer intento fallido, pues el puesto de naturalista ya estaba cubierto ${ }^{63}$. La expedición partió de Kronstadt, en la isla de Kotlin, próxima a San Petesburgo y sede de la flota rusa en el Báltico, el 7 de agosto de 1803. Después de recalar casi un mes en Copenhague, entre el 18 de agosto y el 18 de septiembre, llegaron a Tenerife el 18 de octubre, donde permanecieron hasta el día 27, cuando fueron despedidos por el gobernador y capitán general entre 1803-1809, Fernando Gagigal de la Vega, cuarto marqués de Casa Cagigal ${ }^{64}$. Sin embargo, Langsdorff no completó el trayecto y abandonó el Nadezhda en Kamchatka en 1804 para explorar la costa entre las islas Aleutianas y San Francisco, regresando en 1808 a San Petesburgo. Durante la escala tinerfeña en 1803, conocedor lo que «en el Museo Nacional de París se puede ver una de estas momias naturales [...] tuvimos la suerte de conseguir una para el Museo de San Petesburgo» ${ }^{65}$. La momia la obtuvieron por mediación del gobernador Cagigal, según informó von Langsdorft por carta a Blumenbach desde Tenerife el 25 de octubre de $1803^{66}$. Este inmediato contacto personal sugiere que von Langsdorft, formado también en Göttingen, debía conocer que Blumenbach había conseguido recientemente una momia en 1802 (fig. 6).

Si tenemos en cuenta que el primer marqués de Branciforte, gobernador general de Canarias (1784-88), disponía de varias momias, posiblemente del barranco de Erques (Fasnia), de las cuales pudo elegir una Sylvain Golbéry, «el marqués de Branciforte puso a mi disposición una momia guanche, que tuve la libertad de elegir entre varias otras; mi elección recayó en la de un hombre», es posible que esta momia del nuevo gobernador procediese del mismo grupo.

${ }^{63}$ Krusenstern, A.J. von (1813 [1811-12]): Voyage round the World in the years 1803, 1804, 1805, \& 1806 by order of his Imperial Majesty Alexander the First, on board the ships Nadeshda and Neva. I. London, pp. 28-29.

${ }^{64}$ Krusenstern, A.J. von (1813 [1811-12]), opus cit., n. ${ }^{\circ}$ 63, p. 51.

${ }_{65}$ LANGSDorft, G.H. von (1991 [1813]): Viajes por diferentes partes del mundo durante los años 1803, 1804, 1805, 1806 y 1807. M. Hernández González y J.A. Delgado (eds.). A través del tiempo, 7. La Laguna-La Orotava, pp. 68-69.

${ }^{66}$ Blumenbach, J.F. (1805): «Reisenachrichten vom Hrn. Dr. Langsdorff, von Sanat Cruz auf Tenerife den 25. Oct. 1803». Magazin für den neuesten Zustand der Naturkunde mit Rücksicht auf die dazu gehörigen Hülfswissenschaften, IX (3), pp. 203-206; KLATt, N. (ed.), opus cit., n. ${ }^{\circ} 54$, p. 345 , carta n. ${ }^{\circ} 1627$. 


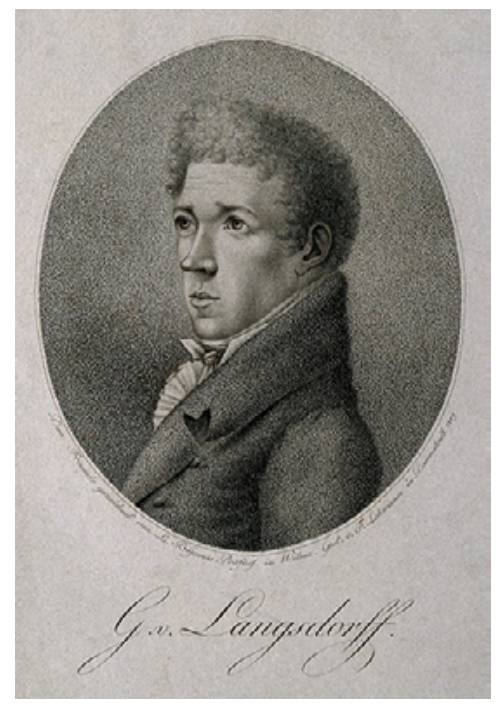

Fig. 6. Barón Georg Heinrich von Langsdorff, médico de la expedición rusa de von Krusenstern que hizo escala en 1803, grabado de F. Lehman (1809).

Esta momia estuvo en los almacenes del Museo Pedro el Grande de Antropología y Etnografía de la Academia de Ciencias Rusa, pasando posteriormente al Museo Hermitage de San Petesburgo, donde actualmente se conserva.

\section{LA MOMIA CON PIERNAS FLEXIONADAS DE TACORONTE EN EL GABINETE DE JUAN DE MEGLIORINI EN SANTA CRUZ DE TENERIFE}

Por una referencia de Sabino Berthelot, conocemos que hacia 1815, "Al principio de este siglo, unos orchilleros descubrieron otra caverna situada en uno de los barrancos de la costa, entre los pueblos de Tacoronte y El Sauzal [...]. Entre las momias que se sacaron de la cueva de Tacoronte, se encontró una cuyo cuerpo había pertenecido a una vieja, y que había sido desecado en una posición acurrucada, las piernas dobladas sobre las rodillas [...]. La cabeza se hallaba cubierta de una capucha y parecía estar bastante bien conservada; los juanetes de la cara se hallaban muy salientes, la frente estrecha y arrugada, la nariz pequeña y la boca muy hendida ${ }^{67}$. Se ha planteado la hipótesis de que su procedencia sería el barranco de

67 Berthelot, S. (1978 [1840-1842]): Etnografía y Anales de la Conquista de las Islas Canarias. Tenerife, p. 96. 


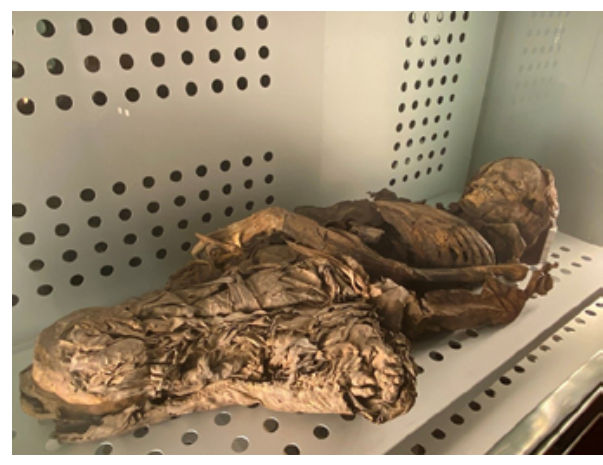

Fig.7a. Momia con los pies flexionados de Tacoronte de un hombre entre 25-29 años. Museo de la Naturaleza y Arqueología de Tenerife.

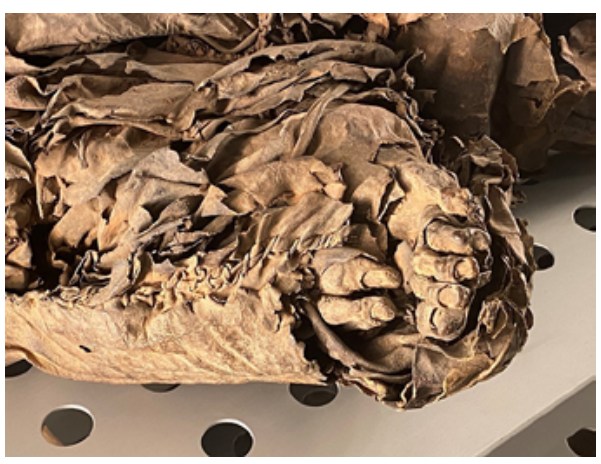

Fig. 7b. Detalle de los pies y del cosido de la piel. Museo de la Naturaleza y Arqueología de Tenerife.

Guayonje ${ }^{68}$, probablemente porque es el barranco casi limítrofe entre ambos municipios, pero ubicado en Tacoronte, siendo el límite el siguiente barranco de Martiño. También se ha propuesto una procedencia de El Sauzal en base a referencias genéricas de Bethencourt Afonso de descubrimiento de momias durante el siglo $\mathrm{XIX}^{69}$. En este sentido, otra opción es que proceda del acantilado de La Garańona ${ }^{70}$, el cual se extiende entre la punta del Camello por la desembocadura del barranco de Guayonje (Tacoronte) hasta la punta de El Sauzal, pero se menciona el cauce bajo de un barranco (figs. 7a-7b).

Este descubrimiento en Tacoronte parece ser también el referenciado en otro libro suyo previo y sugiere por eso una fecha media hacia 1815. "Poco antes de mi llegada a las islas [1820] una nueva necrópolis acababa de ser descubierta: la brutalidad de unos pastores lo había arrasado todo: las momias fueron lanzadas al fondo del barranco de Tacoronte y no se conservaron más que las pieles de las mortajas, de las que se sacaron correas y zurrones. Un aficionado a las antigüedades se trasladó al lugar para rebuscar entre los restos esparcidos por el fondo del barranco: regresó a Santa Cruz con una cabeza y otras piezas anatómicas, que trató de recomponer a su manera. Viajeros que han visitado el gabinete del Mayor Megliorini dudan que el guanche que allí se exhibe está compuesto de distintas piezas, y es posible que

${ }^{68}$ Rodríguez Martín, C. (1995): «Una historia de las momias guanches». I Congreso Internacional de Estudios sobre Momias (Puerto de la Cruz, Tenerife, 1992). I. La Laguna, pp. 153, 160 lám. 1.

${ }^{69}$ FariÑa GonzÁlez, M.A. (1994): «El Museo Casilda de Tacoronte: una pérdida irreparable». Historia del Pueblo Guanche. II. Etnografía y Organización socio-política. M.A. Fariña (ed.). La Laguna, p. 524.

70 Mederos, A. y Escribano, G., opus cit., n. ${ }^{\circ} 4$, pp. 304-306, 328-329. 
bajo la misma envoltura se hayan reunido cuatro o cinco generaciones» ${ }^{71}$. Sobre la reutilización de partes de momias vuelve a insistir después en que "yo no disponía, como el Mayor Megliorini, de miembros de repuesto para sustituir los que le faltaban a nuestra momia $»^{72}$. Esta segunda referencia es importante porque nos indica dos datos importantes, que las piezas fueron recogidas por Megliorini y llevadas a Santa Cruz, no a La Laguna, y nos da una vía lógica para que esta momia acabara en la colección Casilda. Es probable que también comprase otros fragmentos e incluso la momia completa a los descubridores, pues no menciona haber recogido Megliorini una momia completa.

El capitán de origen genovés Juan Megliorini y Spínola se instaló en Santa Cruz de Tenerife desde el 10 de enero de 1799, tras llegar con las tropas del regimiento de infantería Ultonia con soldados irlandeses, donde ejercía de ayudante mayor, procedente del puerto de La Coruña para prevenir la invasión de la isla ${ }^{73}$. Tenía entonces unos 40 años y casi inmediatamente se casó con María del Castillo Iriarte ${ }^{74}$, estableciéndose en la isla aunque el regimiento regresó a la península a finales de $1802^{75}$.

Casi al llegar a Tenerife montó un estudio de pintura que incluía elementos de Historia Natural, como reseńa el vizconde del Buen Paso en agosto de 1800. El «estudio o laboratorio de don Juan Megliorini [...] se adorna de estampas de buenos dibujos, de retratos, herramientas o instrumentos de acero [...] y también algunas curiosidades pertenecientes a historia natural $\aleph^{76}$.

Mientras detentaba el cargo de gobernador del Risco de Canaria, fue nombrado en 1808 sargento mayor de la plaza de Santa Cruz de Tenerife por la Junta Suprema Gubernativa ${ }^{77}$, lo que no fue aceptado por el Cabildo de Gran Canaria que ordenó su ingreso en prisión ${ }^{78}$.

Su interés por la botánica le llevó a ser uno de los que empezaron la aclimatación y cultivo de la cochinilla en Tenerife, con insectos traídos por Isidro Quintero, canónigo de la catedral de La Laguna, «en la huerta de don Juan de Megliorini, aficionado en extremo a las ciencias naturales ${ }^{79}$, lo que contribuyó al inicio de su cultivo desde 1826. Esto le llevó a ser nombrado director de un semillero vivo de madres de cochinilla el 30 de enero de 1828, que con su entrega a los agricultores insulares permitió comenzar desde 1831 las exportaciones ${ }^{80}$.

71 Berthelot, S., opus cit., n. ${ }^{\circ} 17$, p. 76.

72 Berthelot, S., opus cit., n. ${ }^{\circ} 17$, p. 79.

73 León y Xuárez de la Guardia, F.M. ${ }^{a}$ de (1978 [1868]): Apuntes para la Historia de las Islas Canarias 1776-1868. Biblioteca Isleña, 4. Madrid-Tenerife, p. 55.

${ }^{74}$ Primo de la Guerra, J., opus cit., n. ${ }^{\circ}$ 1, p. 52.

${ }^{75}$ León y Xuárez de la Guardia, F.M. ${ }^{a}$ de, opus cit., n. ${ }^{\circ}$ 73, p. 57.

${ }^{76}$ Primo de la Guerra, J., opus cit., n. ${ }^{\circ} 1$, p. 52.

77 León y Xuárez de la Guardia, F.M. ${ }^{a}$ de, opus cit., n. ${ }^{\circ}$ 73, p. 80.

${ }^{78}$ León y Xuárez de la Guardia, F.M. ${ }^{a}$ de, opus cit., n. ${ }^{\circ}$ 73, p. 87.

${ }^{79}$ León y Xuárez de la Guardia, F.M. ${ }^{a}$ de, opus cit., n. ${ }^{\circ}$ 73, p. 220.

${ }^{80}$ León y Xuárez de la Guardia, F.M. ${ }^{a}$ de, opus cit., n. ${ }^{\circ}$ 73, p. 221. 
Paralelamente, hubo entre 1824-1829 un proyecto del cónsul francés, Alexandre Bretillard, de crear un jardín de aclimatación de plantas y del cultivo de la cochinilla, similar al existente en el Puerto de la Cruz, para poderlas trasladar a la colonia francesa del Senegal después de la reconquista del territorio en 1816. Para su dirección propuso a Juan de Megliorini, pues con su ayuda había estado enviando al Senegal diversas plantas de café, caña de azúcar, naranjos y limoneros desde $1819^{81}$.

El Gabinete de Historia Natural de Megliorini estaba instalado en su vivienda de la calle de San José n. ${ }^{\circ} 45$ de Santa Cruz de Tenerife. Entre los primeros viajeros que mencionan una momia en el gabinete están los miembros de la expedición al Polo Sur en la Antártida entre 1819-1821, del contra-almirante ruso de familia alemana nacido en Estonia, Fabian Gottlieb Benjamin von Bellingshausen (Faddéy Faddéyevich Bellinsgauzen), al mando de la corbeta Vostok y su adjunto, Mikhail Petrovich Lazarev, desde la corbeta Mirny, quien ya había circunnavegado el globo entre 1813-1816. La expedición salió de Kronstadt, en la isla de Kotlin, el 4 de junio de 1819. Esta escala en Tenerife ya la había hecho previamente von Bellingshausen como miembro de la expedición rusa de von Krusenstern en 1803 cuando era oficial en la Nadezhda. La expedición es recogida en su libro Double Investigation of the Southern Polar Ocean and the Voyage Around the World (1831).

La segunda visita de la que tenemos constancia la realizó Theophile Frappaz en 1821, mencionando la momia ${ }^{82}$. Más importante es la visita de Jules Sébastien César Dumont d'Urville entre el 13 y el 21 de junio de 1826, que hizo escala en Tenerife a bordo de L'Astrolabe para explorar las costas del Pacífico occidental y buscar el lugar del naufragio de la expedición de La Pérouse que naufragó en las islas Salomón en 1788, a la vez que buscar posibles emplazamientos para una posible colonia penal próxima a las colonias inglesas de Australia. La expedición partió de Toulon el 25 de abril de 1826 y no regresó hasta 1829. Durante su estancia indica que «Por la tarde el cónsul señor Bretillard me acompañó a casa del médico militar señor Megliorini, cuyo gabinete de historia natural me habían elogiado. Y efectivamente, allí encontré una infinidad de objetos, tales como armas, conchas, animales, peces, pájaros y cuadros diversos, todo ello en gran desorden [...]. Lo que más atrajo mi atención [...] fue una momia completa de guanche, que me dijeron que era de una mujer. Estaba envuelta en varias tiras de pieles cosidas, los rasgos del rastro parecían haber sido regulares, las manos muy grandes, y la talla del individuo desecado alcanzaba cinco pies y cuatro pulgadas $[1738 \mathrm{~m}][$ [...] En las grutas sepulcrales de los guanches también se han encontrado bastones de madera dura con empuñadura redonda [...] vasijas de barro y de madera bastante bien torneadas, una suerte de pequeños sellos triangulares de terracota [pintaderas], y sobre todo infinidad de

${ }^{81}$ Le Brun, N. (2016): Un francés entre guanches. Sabino Berthelot y las Islas Canarias. La Orotava, Tenerife, pp. 86-87, 89 .

82 Frappaz, Th. (1824): «Souvenirs d'un jeune marin, ou Récit de plusieurs voyages faits de 1816 à 1822, à la côte de Coromandel et au Bengale, aux îles de France et de Bourbon, aux Seychelles, à Madagascar, etc.». Journal des Voyages, découvertes et navigations modernes, 22 (67), pp. 141 n. ${ }^{\circ}$ 1; Cioranescu, A. (1977): Historia de Santa Cruz de Tenerife. I. Tenerife, p. 223. 


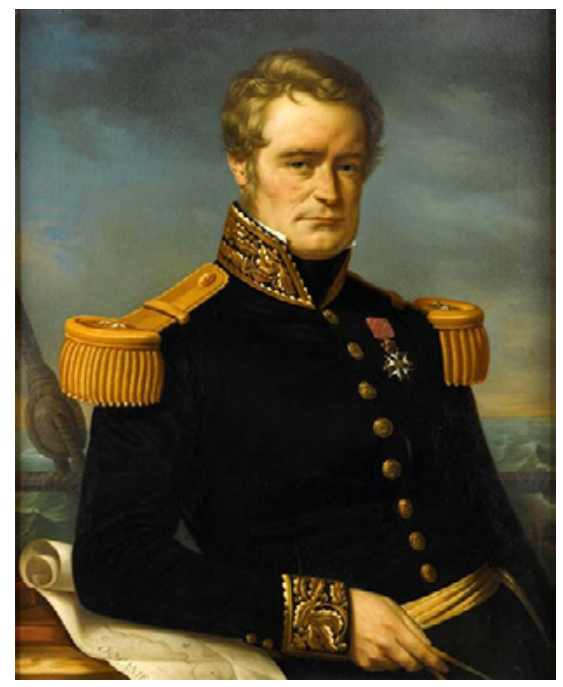

Fig. 8a. Jules Sébastien Dumont d'Urville, al mando de la expedición del L'Astrolabe que hizo escala en 1826. Castillo de Versalles.

pequeños discos del mismo material, con tres renglones de diámetro, ensartados como rosarios [...] agujas de hueso y una especie de tejido trenzado con fibras o cortezas rojizas. A veces se envolvía a las momias con este tejido [...]. El señor Megliorini tenía muestras de todos estos objetos ${ }^{83}$. Es interesante que lo identifique como «médico militar» (fig. 8a).

Esta misma momia fue observada durante la semana del 7 al 14 de noviembre de 1837, en la visita de William R. Wilde, mencionando que era «un famoso museo en Santa Cruz, montado hacía varios años por un viejo comandante español [...] allí tuve la ocasión de ver una pequeña momia femenina, cogida en una cueva hacía algunos ańos en otro lugar de la isla. No parece que se haya utilizado ninguna clase de preparación antiséptica, excepto en las cavidades, que las vaciaban de su contenido y luego las llenaban con semillas, que se supone eran del chenopodium ambrosioides. Se parecía a las momias de la clase baja que más tarde vi en Egipto. El cuerpo estaba envuelto en una piel o cuero» ${ }^{84}$. «En la momia Guanche que tuve la oportunidad de examinar [...] estas tiras de encaje, con las que se decoraba la envoltura, y que formaban parte de la piel en la que estaba envuelta, estaban anudadas

83 Dumont D’Unville, J.S.C. (2000 [1830]): Viaje de la corveta El Astrolabio ejecutado por orden del rey entre los años 1826, 1827, 1827 y 1829, en B. Pico et al. (eds.): Viajeros franceses a las Islas Canarias. Repertorio bio-bibliográfico y selección de textos. La Laguna-Tenerife, pp. 304-306.

${ }^{84}$ WILDE, W.R. (1994 [1840]): «Narración de un viaje a Tenerife». M. Hernández González y J.A. Delgado (eds.). A través del tiempo, 11. Tenerife-La Orotava, pp. 23-24. 


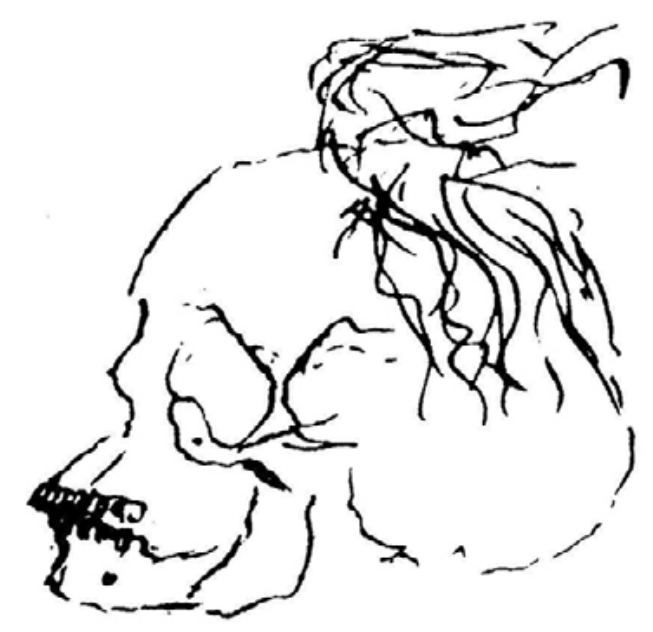

Fig. 8b. Croquis de un cráneo momificado de mujer de 25-35 años en la colección Casilda (Fariña, 1994: 546, 545 fig.), quizás procedente de Tacoronte.

de forma muy peculiar, evidentemente formando algún tipo de dibujo ${ }^{85}$. La nueva referencia a que se trataba de una momia femenina de pequeño tamaño es importante tenerla en cuenta.

En la colección Casilda también había algunas piezas que podían proceder de la colección Megliorini entre las recuperadas en Tacoronte. En este sentido, Berthelot ${ }^{86}$ menciona expresamente que Megliorini recogió «una cabeza» momificada, y en la colección había "Una calavera con parte del cuero cabelludo y con cabello color rojizo, como de una cuarta de largo, fino y ligeramente ondulado, casi lana. El cráneo parece de mujer, y como de 25 a 35 ańos. La parte de cabello corresponde a las puntas más próximas al frontal. Son de un color rubio más subido atrás, que es como achocolatado", IV-8-2, según la descripción de Bethencourt Alfonso ${ }^{87}$. Otra pieza era una "Tibia forrada de cuero y liada con correas del mismo material», IV8-188 (fig. 8b).

No cabe descartar que también tuviera alguna otra momia compuesta a partir de fragmentos de otras momias rotas, ya que poseía varios fragmentos también procedentes de Tacoronte, pues sabemos que había dos momias reconstruidas en la colección Casilda. Una supuestamente procedía del barranco de Badajoz (Güímar),

\footnotetext{
85 Wilde, W.R., opus cit., n. ${ }^{\circ} 73$, p. 63.

86 Berthelot, S., opus cit., n. ${ }^{\circ} 17$, p. 76.

87 Fariña GonzÁlez, M.A., opus cit., n. ${ }^{\circ}$ 69, pp. 545-546, 553.

88 FAriÑa González, M.A., opus cit., n. ${ }^{\circ}$ 69, pp. 545-546, 553.
} 
"completamente restaurada en sus envolturas [...] tendida», IV-7-3, con los dedos de los pies a la vista y abierto en la zona del rostro ${ }^{89}$.

Menos probable es otra que parece que procede del sur de Tenerife porque se conservaba relativamente completa, aunque presenta en el croquis de Bethencourt Alfonso un forrado de piel reciente, que no figura en la fotografía que se dispone de ella. "Está como doblado por el espinazo hacia delante; y la cabeza caída atrás y como sobre el hombro derecho [...] Esta momia la envuelven pieles que indudablemente le fueron puestas hace muy poco tiempo, del cráneo le falta una gran parte por la parte posterior (occipital). Es de cabello rubio [...]. El aspecto de mujer [...] Casi toda la momia es artificial, por más que las partes esenciales del cuerpo pertenecen al mismo individuo", IV-7-2 ${ }^{90}$.

La colección fue comprada por el subteniente de las Milicias Canarias, Sebastián del Jesús Agustín de la Merced «Casilda» Pérez-Yanes Hernández, nacido en Tacoronte el 29 de septiembre de $1792^{91}$. Tenía casa en la calle San José, la misma calle que Megliorini, y la amistad entre ambos, con visitas frecuentes a su gabinete, despertó su interés al coleccionismo. Al fallecer Megliorini, su colección fue puesta en venta, como indica El Atlante de Tenerife del 31 de marzo de 1837, y sus bienes fueron subastados a partir del 2 de junio de 1837, mencionando El Atlante de 31 de mayo que incluían «todos los muebles, enseres y otras cosas curiosas pertenecientes del difunto Coronel D. Juan de Meglioriny, y entre lo que se encuentra un hermoso gabinete de historia natural y una Caja monetaria que contiene medallas y monedas de la mayor antigüedad $»^{92}$. La venta vino obligada porque se había declarado fiador de Matías del Castillo en 1836, deudor de la Hacienda Pública ${ }^{93}$.

El padre del nuevo coleccionista, Sebastián -Casilda- Pérez Yanes, había llegado a ser alcalde de Tacoronte, su pueblo de nacimiento, acumulando una notable fortuna como comerciante de vino y aguardientes entre Santa Cruz de Tenerife y La Habana a donde emigró desde Tacoronte. Esta fortuna la heredó el subteniente Pérez-Yanes Hernández a su muerte, según su testamento en noviembre de $1808^{94}$. Por otra parte, su abuelo materno había sido el alférez José Hernández Ramos de Tacoronte ${ }^{95}$, lo que ayuda a comprender la posterior dedicación militar de PérezYanes Hernández.

Su interés como coleccionista era previo a la compra de la colección Megliorini, siendo un buen bibliófilo, como refleja el hecho de que en noviembre de 1835,

${ }^{89}$ Fariña GonzÁlez, M.A., opus cit., n. ${ }^{\circ}$ 69, pp. 545-546, 553, 557, fot. 6.

${ }^{90}$ Fariña GonZÁlez, M.A., opus cit., n. ${ }^{\circ}$ 69, pp. 547-548, 553, 555, fot. 4.

${ }^{91}$ Bonnet y SuÁrez, S.F. (1991): «El 'Museo Casilda' de Tacoronte y su fundador». Homenaje al profesor Dr. Telesforo Bravo. II. Madrid-La Laguna, p. 115.

92 León Rodríguez, M. ${ }^{a}$ C. (1999): «Noticias de hallazgos de restos arqueológicos del Sur de Tenerife en la prensa insular», en M. Hernández González et al. (eds.): I Jornadas de Historia del Sur de Tenerife (Comarca de Abona) (Arona, 1999). Arona, p. 112, n. ${ }^{\circ}$.

${ }^{3}$ Fariña González, M.A., opus cit., n. ${ }^{\circ}$ 69, p. 524.

94 Barrios Díaz, M. (1998): "Casilda y su Museo». Tacoronte desde sus orígenes (14971997). La Laguna-Tacoronte, pp. 157-158.

95 Bonnet y SuÁrez, S.F., opus cit., n. ${ }^{\circ}$ 91, pp. 115-116. 
desde París, Berthelot después de enviar «recuerdos al amigo Casilda», le comenta al también francés Miguel Maffiotte "pregúntele si quiere cambiar por libros o vender su edición de las cartas de Hernán Cortés a Carlos V», más aún cuando el propio Berthelot reconoce en otra carta de diciembre de 1836 a Maffiotte que «En mi vida errante, cualquier colección me sería gravosa y aun no me ha dado por las bibliotecas ${ }^{96}$. Como comerciante, al disponer de una embarcación propia que hacía la ruta hacia el Caribe explica la notable serie de objetos americanos que tuvo la colección en Tacoronte y también hace comprensible su posterior relación con la familia Le Brun, dedicados al comercio de vinos en Santa Cruz de Tenerife, que heredaron la colección.

La primera referencia que señala la incorporación de la momia flexionada en los orígenes de la colección de Pérez-Yanes Casilda, fue la visita en 1848 de Thomas Debary ${ }^{97}$ quien indica como "lo más curioso para nosotros, una momia; estaba en postura sentada, embalsamada y envuelta en una piel de cabra». La postura sentada solo puede identificarse con la posición doblada de las rodillas, dado que no se conocen en Tenerife momias sentadas en cuclillas, como sucede en ejemplares americanos.

También puede ser la mencionada en 1858 cuando se indica que "yo vi la bellísima momia del rey de Tacoronte que se conserva en un museo privado de Tenerife y que estaba envuelta en ocho capas de piel de cabra» ${ }^{98}$, pues según Bethencourt Alfonso ${ }^{99}$ la "capucha que cubre la cabeza tiene seis envolturas».

Posteriormente vuelve a ser descrita en la colección Casilda en la década de 1870, pues se mantienen dos de los elementos para su identificación: su supuesta atribución a una mujer senil y la posición doblada de las rodillas. «Entre esas momias, se encuentra la de una reina: está acurrucada sobre sus rodillas, en la misma posición que tenía cuando la encontraron. Para verla mejor, he abierto la puerta de cristal del armario en que está encerrada, pero un olor nauseabundo me obligó a cerrarla rápidamente. El rostro está horriblemente contraído; los ojos, las orejas, la nariz, los labios, los dientes, incluso los cabellos, están perfectamente intactos. Estos cabellos son lisos y largos [...]. El cuerpo está envuelto en pieles de cabra, cosidas con tiras de cuero y oscurecidas por el tiempo» ${ }^{100}$.

Estas dos características, mujer y la posición doblada de las rodillas, vuelven a ser mencionadas cuando Olivia Stone visitó la colección Casilda el 30 de octubre de 1883, acompañado por la mujer de Diego Le Brun y sus hijas, además del nuevo propietario de la colección. «Otra momia, de una mujer, que, según dicen, se

96 Rosa Olivera, L. de la (1980): «Correspondencia entre Berthelot y Miguel Maffiotte». Homenaje a Sabino Berthelot en el centenario de su fallecimiento 1880-1980. La Laguna, pp. 133-184.

${ }^{97}$ Debary, Th. (1992 [1851]): Notas de una residencia en las Islas Canarias, ilustrativas del estado de la religión en ese país. M. Hernández González y J.A. Delgado (eds.). A través del tiempo, 8. La Laguna-La Orotava, p. 37.

${ }_{98}$ Mantegazza, P. (2004 [1870]): De Río de la Plata a Tenerife. M. Hernández González y P. Pomares (eds.). Escala en Tenerife, 6. Sevilla-Tenerife, p. 101.

99 Bethencourt Alfonso, J. (1994 [1911]): Historia del Pueblo Guanche. II. Etnografía y Organización socio-politica. M.A. Fariña (ed.). La Laguna, pp. 545-546.

100 Leclerce, J. (1990 [1880]): Viaje a las Islas Afortunadas. Cartas desde las Canarias en 1879. Colección «Clavijo y Fajardo», 8. Madrid, pp. 175-176. 
encontró a medio camino en la cima del Pico, tenía las piernas dobladas hacia atrás por las rodillas, hasta tocar las caderas y, en esa posición, medía tres pies y cuatro pulgadas $»^{101}$. La mención a una supuesta procedencia cercana al Teide, «a medio camino en la cima del Pico» parece estar vinculada a intentar hacer más atractiva la procedencia de la momia a los turistas que, aparte de visitar el museo, a menudo afrontaban la subida al Teide. Esto explica la posterior posible atribución a La Orotava que menciona Bethencourt Alfonso.

Esta momia fue posteriormente descrita con el número 1899 IV-7-1, de la colección Casilda de Tacoronte, donde se mantiene el detalle de la flexión de las rodillas y es por primera vez atribuida correctamente a un hombre: «dicen haberlas encontrado en la Orotava [...]. Lo primero que llama la atención es que se la ve doblada por las rodillas, e inclinada las piernas [...] el pie derecho está debajo del izquierdo [...] y la mano izquierda está como tapando la derecha, como hacia la mitad de los muslos [...] la cabeza caída sobre el hombro izquierdo; y el eje del cuerpo como doblado lateralmente sobre el mismo lado. Algunas de las correas con que le aseguran sus envolturas son del ancho de dos dedos. La capucha que cubre la cabeza tiene seis envolturas; $y$ una de ellas sale como la forma de un abanico abierto, por uno y otro lado, con lo más delgado buscando la parte inferior de la barba, donde se anuda; también tiene algunas correas circulares en derredor del cuello, como para ajustarle las pieles al pescuezo. Los dedos de la mano están como ríspidos. Todo es de color chocolate. El aspecto del semblante y el desarrollo orgánico hacen creer que es hombre» ${ }^{102}$. Esto probablemente explique que Rodríguez Martín et al. ${ }^{103}$ la atribuyan posteriormente a La Orotava, aunque ya habíamos defendido en deta$1 e^{104}$ que se trataba de la momia aparecida entre Tacoronte y El Sauzal a inicios del siglo XIx (fig. 9a-9b).

Por otra parte, dada la especial posición que tenía, «las piernas dobladas sobre las rodillas», y su carácter de hombre adulto, creemos que podemos atribuirla a una de las que se vendieron en 1889 con toda la colección Casilda de Tacoronte a un coleccionista de La Plata en Argentina, para pasar parte de ella después al Museo de la Plata.

Fue el hermano y heredero del coleccionista Diego Le Brun, Carlos Guillermo Le Brun, quien ese mismo año de 1889 pasó a residir a Argentina, el responsable de la venta de la colección al grancanario Fernando Cerdeña por un precio de

101 Stone, O.M. (1995 [1887]): Tenerife y sus seis satélites. I. J. Allen y J.S. Amador (eds.). Valencia-Las Palmas, pp. 496-497.

102 Bethencourt Alfonso, J., opus cit., n. ${ }^{\circ}$ 99, pp. 545-546, 553.

103 Rodríguez Martín, C., Guichón, R., Flegenheimer, N. y Martín Oval, M. (2005): «Forensic anthropological and pathological analysis of the Guanche Mummies from Necochea (Argentina)», en E. Rabino Massa (ed.): VWorld Congress on Mummy Studies. Journal of biological research, 80 (1), p. 101.

104 Escribano, G. y Mederos, A. (2003): «Prospección arqueológica del cauce bajo del Barranco de Guayonje y Camino del Rey (Tacoronte, Tenerife)». Estudios Canarios, 48, pp. 261-264; Mederos, A. y Escribano, G., opus cit., n. ${ }^{\circ} 4$, pp. 215-219. 


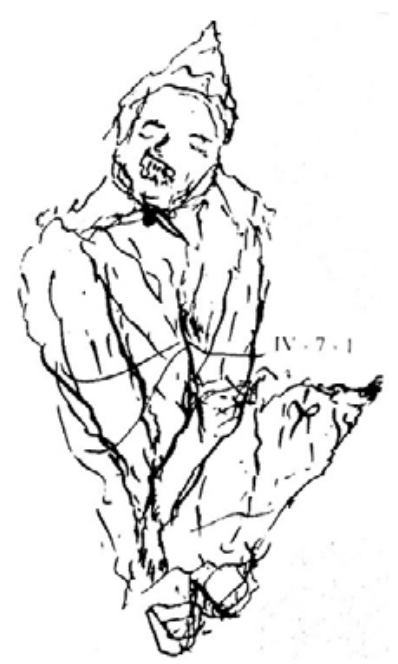

Fig. 9a. Croquis de la momia con los pies flexionados de Tacoronte cuando estaba depositada en la colección Casilda (Fariña, 1994: 546, 545 fig.) Museo de la Naturaleza y Arqueología de Tenerife.

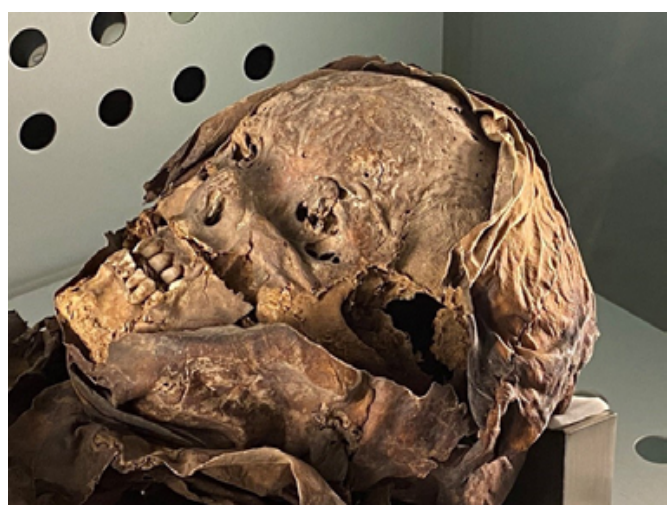

Fig. 9b. Detalle del rostro descubierto de la momia de Tacoronte. Museo de la Naturaleza y Arqueología de Tenerife.

2000 pesos hacia mayo o junio de $1889^{105}$. Fue enviada empaquetada en el vaporcorreo Antonio López de la Compañía Trasatlántica el 20 de julio de 1889, en dirección a Montevideo y Buenos Aires, donde llegó el 12 de agosto entre los 29 cajones que transportaban las piezas ${ }^{106}$. El receptor en Argentina y «encargado de la venta que es Miranda, domiciliado en Buenos Aires» ${ }^{107}$.

La personalidad del comprador, Fernando Cerdeña, la recoge un texto enviado por el propio Grau-Bassas a El Liberal de Las Palmas el 25 de octubre de 1889. "Dentro de breves días quedará instalada en Montevideo una importante institución de crédito, en la que se ha invertido una gran parte de los millones de la señora viuda del capitán general don Máximo Santos. El Acaudalado capitalista español de La Plata, don Fernando Cerdeña, será el presidente de esa institución bancaria, y su vicepresidente, don Lorenzo Mascaró, hermano de la mencionada viuda del general Santos. Como saben nuestros lectores, el señor Cerdeña es un hijo de esta población que disfruta hoy en aquella ciudad de una considerable fortuna ${ }^{108}$.

105 Bonnet y Suárez, S.F., opus cit., n. ${ }^{\circ}$ 91, p. 124.

106 Fariña, M.A. y Tejera, A. (1998): La Memoria Recuperada. La Colección 'Casilda' de Tacoronte en el Museo de Ciencias Naturales de La Plata (Argentina). Tenerife, pp. 20, n. ${ }^{\circ}$ 8, 23, n. $^{\circ} 11$. 107 Alzola González, J.M. (1980): Victor Grau-Bassas, primer conservador de el Museo Canario. Colección Viera y Clavijo, 6. Las Palmas, p. 84.

108 Alzola González, J.M., opus cit., n. ${ }^{\circ} 107$, pp. 85-86, n. ${ }^{\circ} 114$. 
Lamentablemente, eran más las apariencias que la fortuna real y solo un año después, el 11 de diciembre de 1890, Grau-Bassas comenta que "Cerdeña está muy mal de cuartos pero [...] el país está peor ${ }^{109}$, lo que explica sus intentos de vender la colección inmediatamente desde que la compró.

Cuando llegó la colección a Buenos Aires, el antiguo conservador de $E l$ Museo Canario, Víctor Grau-Bassas, fue el encargado de clasificarla y comenta: «He visto el Museo Casilda y es muy bueno, no comprendo como Chil [y Naranjo] dejó de adquirirlo pues hubiera sido una buena adquisición [...] estamos [Gabriel] Garachico y yo encargados de arreglarlo y clasificarlo [...]. Hay cinco ricas momias, magníficas en su conservación [...]. Hay una figurita pequeña, de madera o hueso, que representa un majorero con su vestido y que ha sido encontrada en una cueva de Fuerteventura [...]. Hay bastantes jarros guanches, dos de suela (piel) [...] sólo de los cuadros se podía haber sacado en Canarias los dos mil pesos que costó [...]. Tiene el M.[useo] Casilda una buena colección de anzuelos y otra inmejorable de adornos canarios ${ }^{110}$.

Dos de esas momias fueron donadas en 1927 al Colegio Nacional José Manuel Estrada de Necochea (Argentina), poco años después de su fundación en 1921 como primer instituto secundario de la región, donde quedaron almacenadas y olvidadas. A raíz de la creación de un Museo de Ciencias Naturales en Necochea entre 1973-1980, se inició un primer estudio con rayos X, aunque no se consiguió identificar su procedencia. Sin embargo, al pasar a propiedad estatal el museo, las momias volvieron a ser almacenadas ya que el Museo de Ciencias Naturales del Colegio Nacional estaba entonces cerrado al público. No obstante, la cabeza y un brazo de una de las momias fueron enviadas por la directora del Museo Histórico Regional de Necochea al Museo de Ciencias Naturales de La Plata para continuar buscando su posible procedencia, donde permanecieron hasta 2002. No fueron redescubiertas hasta 1995 por el Grupo de Amigos de la Arqueología, Paleontología, Arqueología y Antropología de Necochea y Quequén, encabezados por el bioantropólogo Ricardo Guichón y la arqueóloga Nora Flegenheimer ${ }^{111}$.

Conocida su existencia durante el Segundo Congreso Internacional de Momias celebrado en Cartagena de Indias (Colombia) en 1995, por comunicación de la arqueóloga Paula Novellino se indicó a los miembros del Museo Arqueológico de Tenerife que contactasen con Ricardo Guichón ${ }^{112}$. Las negociaciones se iniciaron

109 Alzola González, J.M., opus cit., n. ${ }^{\circ}$ 107, pp. 86-88; Farińa, M.A. y Tejera, A., opus cit., n. ${ }^{\circ} 104$, p. 26.

${ }_{110}$ Alzola González, J.M., opus cit., n. ${ }^{\circ} 107$, pp. 85-86.

111 Elichiry, V. (2019): «Complejidades y tensiones del entramado público en una restitución humana (momias guanches, Necochea-Tenerife, 2003)». Revista de Arqueología Histórica Argentina y Latinoamericana, 13 (2), pp. 34, 37, 44.

112 Rodríguez Martín, C., opus cit., n. 68, p. 156; Rodríguez Martín, C., González Antón, R., Martín Oval, M., Rosario Adrián, M.C., Arco, M. ${ }^{a}$ M. del; Arco, M. ${ }^{a}$ del C. del; Guichón, R. y Flegenheimer, N. (2005b): «The restitution of two guanche mummies from Tenerife by Necochea (Argentina)", en E. Rabino Massa (ed.): V World Congress on Mummy Studies. Journal of biological research, 80 (1), p. 270. 
en 2001 y finalmente fueron recuperadas por el Museo Arqueológico de Tenerife, a donde llegaron el 3 de septiembre de $2003^{113}$, con el apoyo de la legislación de restitución del patrimonio cultural que tiene el gobierno argentino para devolver los restos humanos depositados en museos o colecciones privadas a sus comunidades de origen, enviándose a cambio una réplica de la momia en 2004, la cual permaneció almacenada en la aduana argentina hasta 2013, y la entrega de 100000 dólares a la municipalidad de Necochea ${ }^{114}$.

La momia denominada NEC-2 corresponde a un varón adulto, entre 25 y 29 años, de constitución robusta, en posición fetal lateral flexionada y 1,72 $\mathrm{m}$ de altura $^{115}$. Presenta en la cabeza una lesión ósea en el temporal izquierdo o sinusitis frontal, fruto de un tumor maligno o infección ${ }^{116}$, la cual acabó provocándole la muerte. Esto motivó que antiguamente la cabeza fuese separada del tronco para ser objeto de investigación en La Plata. El cuerpo conserva el pulmón, bolsa pericárdica, hígado e intestinos. La momia ha sido datada en 1000 BP, ca. 950 d.C. ${ }^{117} \mathrm{El}$ dato más interesante, y excepcional hasta el momento entre el resto de las momias canarias, es la flexión extrema de las rodillas, que debió realizarse mediante presión cuando el cadáver había fallecido recientemente, quizás para adaptarlo a una cueva de enterramiento con poco fondo.

\section{SABINO BERTHELOT Y LA MOMIA DE GINEBRA}

Sabino Berthelot, futuro cónsul de Francia desde 1847, cuando llegó a Tenerife era un comerciante y no se dedicaba a cuestiones científicas. Nacido el 4 de abril de 1794, fue alumno durante 5 años del Liceo de Marsella entre 1804-1809, alistándose después en la marina de guerra donde permaneció en Toulon como marinero reservista primero y después como suboficial hasta la caída del Primer Imperio de Napoleón en $1814^{118}$. Hijo de un comerciante del puerto viejo de Marsella, salió de su puerto a finales de diciembre de $1819^{119}$ y llegó a Tenerife el 30 de enero de 1820 con 25 años en la bombarda Le Saint-Pierre que había fletado, con 105 toneladas de mercancías, junto con la goleta La Virginie que transportaba 60 toneladas del comerciante Louis Marius Burle. El 12 de marzo de 1820 firmaron un contrato privado de asociación y la goleta La Virginie continuó su viaje al Senegal y Cabo

${ }^{113}$ Rodríguez Martín, C. et al., opus cit., n. ${ }^{\circ} 112$, pp. 270-271.

114 Elichiry, V. (2018): «Procesos de identificación y representaciones patrimoniales. En la trama de la restitución de dos momias guanches desde Necochea (Buenos Aires) hacia Tenerife (Islas Canarias), entre 2001 y 2004». Arqueología, 24 (1), p. 257; Elichiry, V., opus cit., n. ${ }^{\circ}$ 109, pp. 34, 36-37.

115 Rodríguez Martín, C., Guichón, R., Flegenheimer, N. y Martín Oval, M., opus cit., n. ${ }^{\circ}$ 103, pp. 101.

116 Rodríguez Martín, C. et al., opus cit., n. ${ }^{\circ}$ 103, pp. 102-104, 103, fig. 2.

117 Rodríguez Martín, C. et al., opus cit., n. ${ }^{\circ}$ 103, pp. 101.

${ }^{118}$ Le Brun, N., opus cit., n. ${ }^{\circ} 81$, pp. 63, 66 y 68.

119 Berthelot, S., opus cit., n. ${ }^{\circ} 17$, p. 19. 
Verde el 13 de marzo. En cambio, Le Saint-Pierre que había pasado buena parte de su cargamento a la goleta, cargó vino, orchilla, barrilla y palo rosa para regresar a Marsella ${ }^{120}$. En el cargamento, con un valor de 60000 francos, lo más valioso eran las mercancías ilegales, 29 barriles de pólvora, un cañón, 2 cajas de hojas de puñales de hierro que habían sido embarcadas como cajas de licor y 7 barriles de tabaco en puros, probablemente para negociar con tratantes de esclavos en el entorno de Senegal ${ }^{121}$. El comercio negrero estaba prohibido desde el 29 de marzo 1815 por Napoleón I, aunque la abolición de la esclavitud en sus colonias no se materializó hasta el 27 de abril de 1848.

Después de esta estancia de dos meses, tanto Berthelot como Burle decidieron instalarse en Tenerife como négociants, pero sin poder regresar a Francia por tener Berthelot deudas contraídas de al menos 8000 francos, que tuvo que pagar P.B. Webb al llegar a la frontera francesa en 1830 (borrador de carta de Webb) ${ }^{122}$. Sin embargo, la crisis política generada para poner fin al Trienio Liberal, a fin de imponer un gobierno absolutista por parte de Fernando VII, fue apoyado por Luis XVIII de Francia, quien envió a los 100000 hijos de San Luis, 95000 soldados al mando del duque de Angoulema desde el 7 de abril de 1823, los cuales acabaron cercando Cádiz y bombardeándola durante agosto y septiembre con el rey dentro. Para poder salir con seguridad, Fernando VII prometió que respetaría la Constitución de 1812, pero con la ciudad casi derrotada, se unió a las tropas francesas y decretó la abolición de la Constitución el 1 de octubre. De este ejército, 45000 soldados franceses inicialmente permanecieron en Espańa, realizando una evacuación progresiva de efectivos que se prolongó hasta 1828.

Esta situación de guerra llevó al colapso del comercio, indicando el cónsul francés Alexandre Bretillard en Tenerife que ya está paralizado en noviembre de $1823^{123}$, lo que tuvo que afectar a los negocios de Berthelot y Burle.

$\mathrm{Al}$ año siguiente, Berthelot pasó a vivir a La Orotava en un sector de la casa de Gaspar de Franchi Mesa y Ponte ${ }^{124}$, para participar en la creación de un liceo que se anunció el 1 de mayo de 1824 y comenzó sus clases a inicios del curso académico 1824-1825. Al liceo se incorporó también como profesor Domingo Saviñón, mientras Berthelot impartía clases de Botánica, pero el centro fue cerrado el 18 de abril de $1825^{125}$. El proyecto fracasó por los impedimentos del estamento religioso,

${ }^{120}$ Le Brun, N., opus cit., n. ${ }^{\circ}$ 81, pp. 78-79; Hernández González, M. (1998): «El liceo de La Orotava (1824-1827), una experiencia pedagógica liberal en la década ominosa bajo la dirección de Berthelot y Auber». Revista de Ciencias de la Educación, 173, p. 87.

${ }^{121}$ Le Brun, N., opus cit., n. ${ }^{\circ} 81$, pp. 79-81, n. ${ }^{\circ} 10$.

122 Berthelot, S. (2016 [1829-52]): Cartas inéditas de S. Berthelot a P.B. Webb. Reconstruyendo una aventura editorial: La Historia Natural de las Islas Canarias. En P. Suárez, A. Relancio y A. Santos (eds.). Tenerife, p. 163; Le Brun, N., opus cit., n. ${ }^{\circ} 81$, pp. 82 y 84.

${ }^{123}$ Le Brun, N., opus cit., n. ${ }^{\circ} 81$, p. 82.

124 Berthelot, S., opus cit., n. ${ }^{\circ}$ 17, p. 71.

125 Berthelot, S., opus cit., n. ${ }^{\circ}$ 17, pp. 46-47; Rodríguez Mesa, M. (1980): «1820-1830. La primera época de Sabino Berthelot en Tenerife». Homenaje a Sabino Berthelot en el centenario de su fallecimiento 1880-1980. La Laguna, pp. 111, 114; HernándEZ GonZÁleZ, M., opus cit., n. ${ }^{\circ}$ 118, p. 91. 
encabezado por el obispo Linares y la autoridad militar al mando del comandante general Teodoro Uriarte ${ }^{126}$. Al quedarse sin fuentes de ingreso, el marqués de Villanueva del Prado nombró a Berthelot segundo director del Jardín Botánico del Puerto de la Cruz, tras proponérselo al primer ministro o Secretario de Estado, Francisco de Paula Cea Bermúdez el 6 de junio de 1825, un jardín botánico para el cual Berthelot llegó incluso a sugerir su adquisición por Francia en $1827^{127}$. Este cargo fue la razón básica que le dio prestigio científico en Europa con el paso de los años, debido a las sucesivas visitas de especialistas extranjeros que hacían escala en Tenerife, y ya como segundo director recibió a Dumont D'Urville en junio de $1826^{128}$.

Antes de pasar a residir a La Orotava en el verano de 1824, pues indica claramente que «yo residía entonces en Santa Cruz» ${ }^{129}$, realizó una exploración para localizar una momia en una cueva cercana a Santa Cruz de Tenerife, pues hasta 1825 no inició exploraciones más detalladas en la isla con el nuevo cónsul de Gran Bretaña desde julio de 1825, Francis Coleman Mac-Gregor ${ }^{130}$. No obstante, se ha sugerido que la búsqueda de la momia fue ya residiendo en La Orotava hacia $1826^{131}$, probablemente por la mención de que «Han transcurrido cinco ańos después. Vengo de recorrer las costas de Argelia» y por una carta de Berthelot ${ }^{132}$ que indica que visitó Ginebra en 1831. Sin embargo, creemos que Berthelot en su carta debe confundirse ligeramente de fechas, pues la prospección corresponde a su fase claramente coleccionista previa.

La búsqueda de una momia se realizó en un emplazamiento próximo al puerto Santa Cruz de Tenerife, en la desembocadura del barranco de Valleseco, una zona actualmente muy afectada no solo por la desembocadura del barranco con el barrio del mismo nombre, sino también por el desmonte parcial de los cerros más inmediatos a la costa por el trazado de la carretera entre Santa Cruz y San Andrésplaya de Las Teresitas. Debe tratarse de alguna de las cuevas que están en lo alto del cerro derecho u oriental del barranco de Valleseco, a unos $60 \mathrm{~m}$ de altura, pues las cuevas de la parte inferior han sido reutilizadas y algunas cerradas (fig. 10).

«Manuel 'el Orchillero' [...]. Pasaba por ser el más audaz entre sus compañeros, que le habían puesto por sobrenombre 'La Andoriña'. Me puse de acuerdo con él para visitar alguna gruta funeraria que no hubiese sido profanada: necesitaba un guanche al precio que fuese, y el decidido muchacho inició la búsqueda de una gruta: una escopeta de caza y diez pesetas sería la recompensa [...]. Llevaba Manuel

126 Dumont D’Urville, J.S.C. (1990 [1834-1835]): Viaje pintoresco alrededor del mundo. Resumen general de los viajes y descubrimientos. J.A. Delgado (eds.). A través del tiempo, 6. La LagunaLa Orotava, p. 123; Berthelot, S., opus cit., n. ${ }^{\circ} 17$, p. 47.

127 Le Brun, N., opus cit., n. ${ }^{\circ}$ 81, p. 121; Berthelot, S., opus cit., n. ${ }^{\circ} 17$, p. 74.

128 Dumont D’Urville, J.S.C., opus cit., n. 83, p. 302; Berthelot, S., opus cit., n. ${ }^{\circ} 17$, pp. 74.

\footnotetext{
129 Berthelot, S., opus cit., n. ${ }^{\circ} 17$, p. 77.

130 Berthelot, S., opus cit., n. ${ }^{\circ} 17$, p. 55.

131 Le Brun, N., opus cit., n. ${ }^{\circ} 81$, p. 153, n. ${ }^{\circ} 40$.

132 Berthelot, S., opus cit., n. ${ }^{\circ} 122$, p. 43.
} 


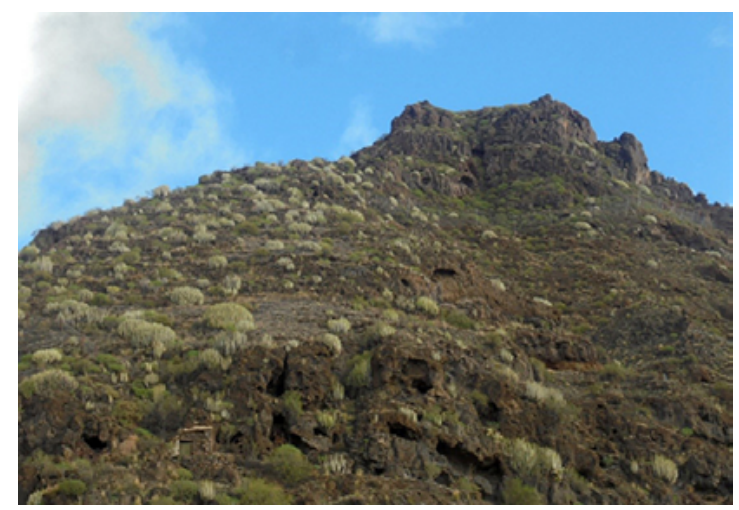

Fig. 10. Cuevas en la margen oriental de la desembocadura del barranco de Valleseco (Santa Cruz de Tenerife).

más de tres meses en el campo y no había dado señales de vida [...] cuando una tarde el mismo Manuel vino a anunciarme que había descubierto momias en una cueva hasta entonces ignorada [...]. Fuimos por la orilla del mar hasta la desembocadura del Barranco de Valleseco [Anaga, Santa Cruz de Tenerife] [...]. Por fin, llegados al pie del morro de La Corona [...] la cueva de Manuel, emplazada en una formación basáltica, daba la impresión de estar a más de doscientos pies del suelo [ca. $61 \mathrm{~m}$ altura] [...]. El interior de esta cavidad tenía alrededor de diez pasos de ancho por quince de profundidad y la bóveda era lo suficientemente alta para que pudiéramos estar de pie [...]. Manuel acabó por descubrir una oquedad donde encontramos dos vasos cerámicos [...]. No lejos de allí recogí una especie de bolita artísticamente trabajada [...]. Nos faltaba por explorar un rincón. Los dos viejos orchilleros encendieron un hachón [...]. Era un guanche [...]. Yo me apresuré a retirar la parihuela carcomida sobre la cual descansaba, llevamos la momia a la entrada de la cueva para examinarla a plena luz [...]. Aparecía envuelta en tres pieles de cabra sujetas con fuertes correas, y llevaba un capuchón sobre la cabeza: el busto estaba bien conservado, los tejidos se conservaban todavía intactos, pero la cara la tenía horriblemente desfigurada. Le faltaban los brazos y las piernas [...] volvimos al interior de la cueva para proseguir nuestra exploración 'Puede haber más cuerpos bajo esta capa de tierra [...] la azada [...] nos vino de maravilla. Al principio sólo encontramos pieles y astillas de sabina y tea. Pero he aquí que los compañeros de Manuel tropiezan con un cráneo y retroceden despavoridos. No hay manera de hacerles trabajar. A cada pedazo de hueso que se desentierra, se presignan y aconsejan dar por terminado el trabajo [...].

No podíamos bajar la momia al barranco con la cuerda que debía servir para nuestro descenso, ya que era preciso sujetarla con varias vueltas [...]. Transportarla nosotros mismos era el único recursos que nos quedaba [...] al descender, a vuelo de pájaro, un abismo de doscientos pies de profundidad [...] la momia, a la que se le había roto el cuello en el descenso. A cada movimiento del orchillero, la cabeza bamboleante del guanche le golpeaba en la espalda [...]. Esta momia, conseguida después de tantas fatigas, acabó hecha una ruina. Yo no disponía como 


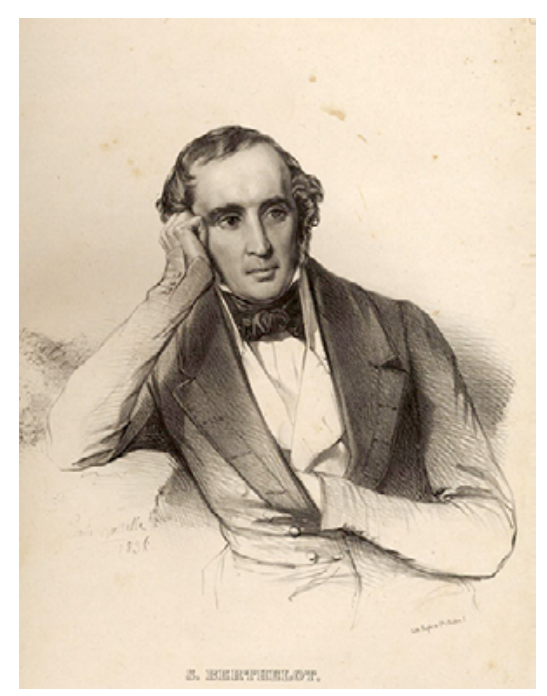

Fig. 11. Sabino Berthelot, grabado por Émile Lassalle (1838).

el Mayor Megliorini, de miembros de repuesto para sustituir los que le faltaban a nuestra momia. Se la regalé a Manuel, en la esperanza de que pudiera procurarme otra mejor conservada. Mi orchillero se la vendió a un extranjero en el puerto de la Orotava, un comprador menos exigente. A partir de entonces todas mis exploraciones fueron infructuosas. Dejé Tenerife llevándome el recuerdo de mi guanche y el pesar de haberme desprendido de él de forma tan poco razonable.

Han transcurrido cinco años después [...] llegué a Ginebra. Durante mi estancia en esta ciudad visité el Gabinete de Historia Natural, y entre los objetos raros allí reunidos me enseñaron una momia canaria. ¡Que casualidad! Era mi guanche, que seguía baldado y sin brazos, y con su cabeza abatida. Lo reconocí en el acto. El comerciante suizo que lo había adquirido en La Orotava, acababa de donarlo al Gabinete. Fue el profesor Decandolle quien me lo confirmó» ${ }^{133}$.

A inicios de junio de 1831 llegaron a Ginebra, P.B. Webb y Berthelot ${ }^{134}$. En la ciudad, Augustin Pyrame de Candolle, catedrático de Botánica y Zoología en Ginebra entre 1816-1834, había sucedido en Broussonet en su cátedra de Botánica en la Universidad de Montpellier antes que acceder a la cátedra en Ginebra, por lo que debía conocer las dos momias presentes en Montpellier y no cabe descartar una relación entre el comerciante suizo y el catedrático de Candolle, que propició que la momia llegase al Muséum d'histoire naturelle de Genève, aunque las colecciones egipcias están depositadas en el Musées d'art et d'histoire de Genève (fig. 11).

\footnotetext{
133 Berthelot, S., opus cit., n. ${ }^{\circ} 17$, pp. 77-79.

134 Berthelot, S., opus cit., n. ${ }^{\circ} 122$, p. 43 carta 2.
} 


\section{LA MOMIA DEL GABINETE DE HISTORIA NATURAL DE LA UNIVERSIDAD DE SAN FERNANDO Y EL INCREMENTO EN LOS DESCUBRIMIENTOS DE ENTERRAMIENTOS ENTRE $1825-50$}

Tenemos una referencia a una momia en un gabinete de Historia Natural al menos desde 1825, pues se indica que durante «mi primera visita a la Universidad de San Fernando [...] situémonos en 1825 [...] [en] el Convento de San Agustín [...]. El Gabinete de Historia Natural forma parte de la Biblioteca [...] Y en medio de ese caos aparecen los tristes despojos de un pobre guanche agujereado por la polilla ${ }^{135}$. La fecha de 1825 parece ajustarse a la reanudación de los cursos a finales de $1825^{136}$ después del cierre universitario el 2 de diciembre 1823 y su reapertura el 4 de noviembre de $1825^{137}$. No obstante, Berthelot había llegado a Tenerife en 1820 , frecuentaba la casa de Domingo Saviñón, profesor de la Universidad, que se había trasladado a la sede del convento de San Agustín en 1821, y resulta dudoso que no hubiera visitado la sede universitaria antes de desplazarse a vivir en La Orotava en el verano de 1824. Lo más lógico sería que después de verla quiso conseguir una momia propia que encargó tres meses antes y situaría la visita y el encargo en torno a 1823. En cualquier caso, su antigüedad parece sugerir un hallazgo de finales del siglo XVIII o inicios del siglo XIX y la opción más probable sería una de las momias de El Sauzal, de las cuales una completa se quedó en poder de Saviñón, quien por entonces ya tenía 56 años y quizás acabó depositándola en la universidad.

Esta momia vuelve a ser citada en un inventario de 1847 del Instituto de Canarias, donde se menciona "una momia de guanche maltratada', un pie y una mano igualmente momificados», fragmentos de otra momia que podrían tener similar origen en El Sauzal. La momia vuelve a ser mencionada en un inventario de 1861 y se describe como momia "incompleta y mal conservada»" ${ }^{138}$ (figs. 12a-12b).

Sin embargo, hay toda una serie de menciones a hallazgos de restos humanos donde no queda claro si se trata de enterramientos o bien de momias, ya que muchas veces suele hablarse de momias cuando solo se han descubierto esqueletos humanos.

Entre ellos cabría citar el primero en 1825. «la pequeña aldea de Chinama [Chińama, Granadilla de Abona] [...] un barranco muy escarpado, situado a poca distancia por el lado oeste, en cuyas paredes verticales, y a diferentes alturas, había abiertas muchas cuevas llenas de momias guanches. Montones de huesos de esas momias formaban pequeñas colinas al pie de las cuevas» ${ }^{139}$, donde de lo que se habla es de «montones de huesos». Es posible que corresponda a «el risco Bermejo

135 Berthelot, S., opus cit., n. ${ }^{\circ} 17$, pp. 50-52.

136 Berthelot, S., opus cit., n. ${ }^{\circ}$ 17, p. 49.

137 Núñez Muñoz, M. ${ }^{a}$ F. (1986): La Universidad en Canarias. Una aproximación a su evolución histórica. La Laguna-Tenerife, p. 26.

138 Fajardo Spínola, F. (1995): Historia del Instituto de Canarias. Tenerife, pp. 131-132.

139 Buch, L. von (1999 [1825]): Descripción Física de las Islas Canarias, en M. Hernández González y J.A. Delgado (eds.). A través del tiempo, 17. La Orotava-La Laguna, p. 26. 

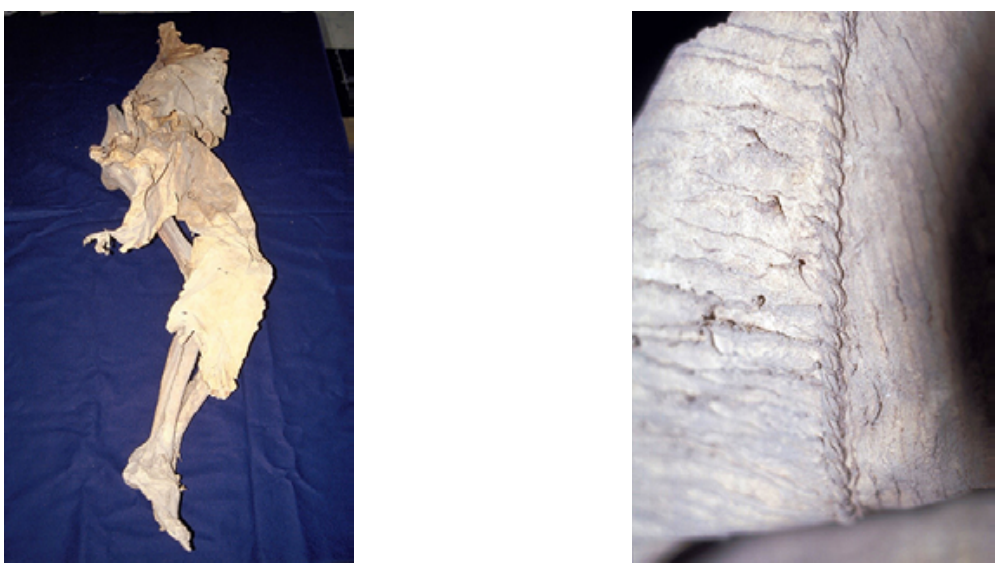

Figs. 12a-12b. Momia y detalle del cosido de la piel. Instituto Cabrera Pinto. La Laguna.

de la montaña de Chiñama [Granadilla, donde] se encontraron otras dos en buen estado» ${ }^{140}$, que podrían ser momias, pero también cuerpos esqueletizados.

Un segundo caso sucedió al año siguiente en 1826. "Según carta dirigida a D. Sebastián Yanes Casilda por D. Salvador de Zárate, administrador de la CasaFuerte de Adeje por año 1830; compró el sr. Zárate una lanza a un hombre que la había encontrado por el año 26 de este siglo en el barranco de Herque (junto a Guía), en una cueva con unas 40 momias, que arrojó de la cueva para aposentar su ganado, porque la lluvia y el viento lo obligaban. Junto a una de las momias, que estaban tendidas sobre maderas del monte, encontró una especie de lanza, muy bien labrada de adornos, que remataba en uno de sus extremos como por un ganiguito, del mismo palo y madera, vuelto hacia abajo; ganiguito que quitó y tapó con cera sus rasgaduras; y le puso por el otro extremo una argolla, con objeto de usar el palo. ¿Sería ésta una añepa? Se conserva en Gabinete de D. Sebastián Casilda» ${ }^{141}$. Se habla de «40 momias» arrojadas, pero de ningún resto humano bien preservado y probablemente sean 40 enterramientos. El barranco de Erques es un gran barranco de cumbre que separa el municipio de Adeje del de Guía de Isora.

Un tercer hallazgo sucedió diez ańos después. "Por el año [18]35» cuando «descubrieron una cueva tapiada en el barranco de Amara que conservaba las camas de los guanches [...] cuatro majanos alargados [...] con dos maderos a lo largo encima y varios atravesados; sobre esto ramas menudas y encima de todo pieles de cabras» ${ }^{142}$. Allí aparecieron "cuevas con momias guanches echadas una en el suelo y otras sobre pequeñas paredes» ${ }^{143}$. Estas "paredes» eran 3 "poyos de piedra hechos con bastante

\footnotetext{
140 Bethencourt Alfonso, J., opus cit., n. ${ }^{\circ}$ 99, p. 601.

141 Bethencourt Alfonso, J., opus cit., n. ${ }^{\circ}$ 99, p. 540.

142 Bethencourt Alfonso, J., opus cit., n. ${ }^{\circ}$ 99, p. 456.

143 Bethencourt Alfonso, J., opus cit., n. ${ }^{\circ}$ 99, p. 387.
} 


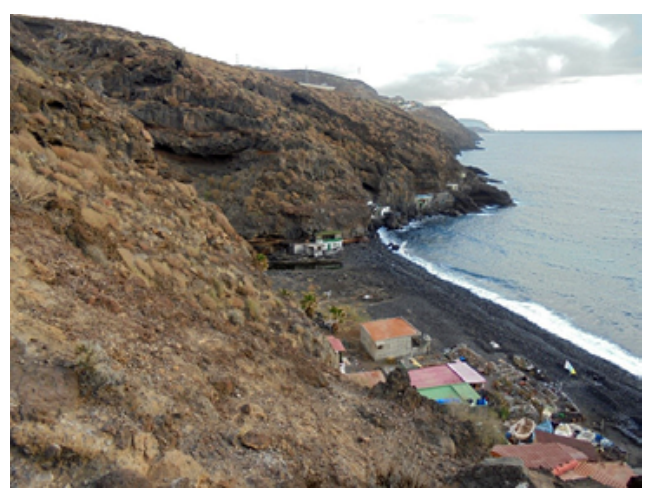

Fig. 13. Playa del Muerto (Santa Cruz de Tenerife), donde se localizaron dos cuevas funerarias en 1836, una de ellas con 8 capas de enterramientos superpuestos, actualmente reutilizadas.

esmeros, arrimados a las paredes [...] como de 2 metros de largo, $0,50 \mathrm{~cm}$ de alto y 0,60 centímetros a 1 metro de anchos [...] sobresaliendo como una tercia del fondo embaldosado con lajas. En estos poyos apilaban las momias» ${ }^{144}$, aunque en otra ocasión no se habla de momias sino que se identificaron «los restos de tres cadáveres sobrepuestos ${ }^{145}$. Nuevamente aquí nos encontramos con una referencia oral donde no se especifica ningún resto antropológico momificado y se habla de tres cadáveres o tres momias, alguno sobre pieles de cabra en unos poyetes de piedra. El barranco de Amara discurre paralelo al barranco del Rey, que es mucho más profundo y es el actual límite entre los municipios de Arona y Adeje, aunque presenta algunos saltos en su cauce que dificultan el descenso, lo que hace más probable que la cueva se encontrase en el cauce inferior, cercano al punto de confluencia.

Un año después se menciona otro hallazgo en 1836. «Al Sur de Hoya Fría, en la playa del Muerto, se descubrieron hacia 1836 tres cuevas de guanches, dos de ellas usadas como cementerio. Una estaba llena de cadáveres dispuestos en ocho camadas, una encima de otra; todas las momias fueron tiradas al mar, según el Diccionario geográfico de P[edro]. M.[ariano] Ramírez [y Atenza, manuscrito en la Biblioteca Municipal de Santa Cruz]» ${ }^{146}$. Este caso es aún menos probable, supuestamente habrían dos cuevas funerarias y en una de ellas se menciona que habían enterramientos superpuestos en 8 capas, pero tampoco se menciona ningún resto humano momificado concreto. Esta playa tiene un acceso difícil por tierra, descendiendo por el cauce del barranco o el paralelo desde el cual se accede a la playa, por lo que es posible que hayan llegado con una pequeña barca. Actualmente hay algunas cuevas en el margen occidental que se abren sobre la playa, en su parte superior, pero están reutilizadas como infraviviendas (fig. 13).

${ }_{144}$ Bethencourt Alfonso, J., opus cit., n. ${ }^{\circ}$ 99, pp. 301 y 599.

145 Bethencourt Alfonso, J., opus cit., n. ${ }^{\circ}$ 99, pp. 301 y 598.

146 Cioranescu, A., opus cit., n. ${ }^{\circ} 82$, p. 356 , n. ${ }^{\circ} 16$. 
En 1845 vuelve a citarse otro descubrimiento de un enterramiento. «En el año 1845 me escribió el Sr. Prebendado D. Antonio Pereyra Pacheco, venerable cura del lugar de Tegueste, lamentando la rusticidad destinada de nuestra gente con respecto a los restos de las momias y utensilios de los antiguos Guanches que por casualidad de vez en cuando suelen encontrarse, y dice así la carta [...] 'en una cueva eminente en el risco llamado la Atalaya, en la que solamente colgados con sogas pueden entrar, una mujer de Tejina (casada hoy con D. Felipe Carvallo), tuvo la osadía de penetrarla para sacar el polvo que ellos llaman carambola con el que abonan las tierras algunos en Tejina, encontróse un cuerpo entero y bien conservado de una guancha, y su ilustración le sugirió la idea de arrojarla desde la entrada hasta verla caer abajo en polvo'» ${ }^{147}$. El tratarse de un único cuerpo "entero y bien conservado» podría hacer pensar en una posible momia femenina, pero nuevamente podría también tratarse de un esqueleto completo con pieles debajo para no contactar con la tierra. La Atalaya corresponde a la Mesa de Tejina, que presenta varias cuevas en su parte superior, alguna también utilizada en época aborigen como cueva de habitación.

En cambio, un descubrimiento de 1847 sí se trata con seguridad de restos momificados. «En la misma cueva del barranco del Agua, encontró el pastor de Ifonche [Adeje] (Sr. Francisco, hombre veraz y observador, al que aludo arriba) varias momias, pero una se conservaba perfectamente, allá para el año 47 (1847) en que la descubrió. Dentro de la cueva el sepulcro estaba formado de lajas espetadas de canto en el suelo, del que sobresalían como una tercia, figurando como un ataúd, y teniendo como pavimento una capa de lajas bien dispuestas. Dentro se encontraba tendida una momia envuelta en siete zaleas, cubierta de ramas de ajafo. Las coyunturas, a raíz de la piel del cadáver las tenía embadurnadas con bálsamo negro, en las rodillas, codos, etc. El cabello suelto y de un color tirando a rubio. Muchas debieron estar dispuestas como éstas pero estaban destrozadas, así como las lajas que formaban los cajones» ${ }^{148}$. Este ajafo era el leñanoel o palo rosa, un «leńanoel, [que] denominan leña santa, porque los guanches la elegían como combustible por su fragancia para alimentar las hogueras sagradas en sus ritos ${ }^{149}$.

Aunque se mencionan "varias momias», una es claramente descrita con siete capas de piel que indica un individuo importante por el cuidado en la momificación, que nos recuerda a una de las presentes en Erques (Fasnia) con «nueve mortajas» ${ }^{150}$. Es interesante que no mencione su destrucción y el relativo detalle en su descripción quizás sugiere que la momia se conservó.

147 Álvarez Rixo, J.A. (1990 [1845-79]): Apuntes sobre restos de los guanches encontrados en el siglo actual, en A. Tejera (ed.). Eres (Arqueologia), 1 (1), p. 122.

148 Bethencourt Alfonso, J., opus cit., n. ${ }^{\circ}$ 100, p. 602.

149 Bethencourt Alfonso, J. (1991 [1912]): Historia del Pueblo Guanche. I. Su origen, caracteres etnológicos, históricos y lingüisticos. M.A. Fariña (ed.). La Laguna, p. 304, n. 54.

150 Anchieta y Alarcón, J. de (1735-67/2017): Cuaderno de citas. III, en D. García Pulido (ed.). Tenerife, p. 15 GHI-21. 


\section{CONCLUSIONES}

La exhibición de dos momias guanches en el Gabinete de Historia Natural del Jardín de Plantas de París, incorporadas entre 1772-76, despertó el interés de diversas expediciones científicas que hicieron escala en Tenerife en la primera mitad del siglo xIx. La expedición de Nicolas Baudin en 1800 coincidió con el descubrimiento de una cueva con momias en El Sauzal, una de las cuales fue trasladada al gabinete científico del doctor Domingo Saviñón en La Laguna y la mayor parte fueron adquiridas por el vicecónsul de Francia, Louis Gros. La inmediata llegada de la expedición Baudin propició que tres momias fueran entregadas a los expedicionarios por el cónsul francés y botánico Auguste Broussonnet. Una la recibió el dibujante Jacques Gérard Milbert, quien la acabó tirando al mar, otra se entregó a varios expedicionarios que la dividieron en pedazos para repartírsela y una tercera para su estudio a Jean-Baptiste Bory de Saint-Vincent, quien se la devolvió a Broussonnet antes de partir, por lo que probablemente optó después por enviarla en 1801 a un amigo, el naturalista J. Banks de Londres. Sir Joseph Banks se la ofreció a su vez al doctor y antropólogo Johann Friedrich Blumenbach, de la Universidad de Göttingen en 1802, donde actualmente se conserva. Otras dos momias fueron enviadas a la universidad de Montpellier donde se incorporó Broussonnet a la cátedra de Botánica en 1803, actualmente conservadas en el museo de la facultad de Medicina.

Un año después, otra momia fue entregada por el gobernador y marqués de Casa Cagigal a la expedición rusa de von Krusenstern en 1803, actualmente depositada en el museo Hermitage de San Petesburgo, y quizás procedía de las últimas momias extraídas de la cueva de Erques en Fasnia, descubierta en 1764, que mandó recuperar su predecesor el gobernador y marqués de Branciforte.

Una nueva cueva con momias se descubrió $c a .1815$ en Tacoronte, algunas de las cuales fueron compradas y otros fragmentos recuperados por Juan de Megliorini para su gabinete científico en Santa Cruz de Tenerife. Al morir, su colección fue puesta a la venta en 1837 y fue adquirida por un amigo, Sebastián «Casilda» Pérez-Yanes Hernández, que la expuso en Tacoronte hasta que falleció en 1868. La colección la heredó Diego Le Brun, quien la mantuvo expuesta hasta su muerte en 1887 y fue heredada por Carlos Guillermo Le Brun. Al pasar a residir en Argentina en 1889, la vendió. La momia más completa, un hombre con las piernas flexionadas, terminó en el museo de Necoechea en Argentina, hasta su devolución a Tenerife en 2003.

Otra momia se localizó en Valleseco, Santa Cruz, hacia 1823, por un rastreador pagado por Sabino Berthelot, pero al partirse su cuello mientras era descendida desde la cueva, fue descartada por Berthelot, quien esperaba encontrar en un futuro otra momia en mejores condiciones. Por esta razón, la momia fue vendida en el Puerto de la Cruz a un comerciante suizo y actualmente se conserva en Ginebra.

Finalmente, se menciona el descubrimiento en el barranco del Agua (Adeje) de una cueva en 1847 con al menos una momia, que parece corresponder a un individuo importante, pues estaba rodeado de 7 capas de pieles. Si tenemos en cuenta 
que según su reconstrucción experimental cada capa exigía 6 o 7 pieles de cabra ${ }^{151}$, esto implicaría las pieles de 42 o 49 animales.

En otros posibles hallazgos es difícil saber si son restos de esqueletos o de momias, dada la habitual confusión entre los informantes que continúa hasta la actualidad. Esto sucede con dos individuos de risco Bermejo en Chiñama (Granadilla) en 1825, los cuarenta muertos del barranco de Erques (Guía de Isora-Adeje) en 1826, los tres del barranco de Amara (Arona) en 1835, las ocho "capas» con enterramientos de la playa del Muerto (Santa Cruz de Tenerife) en 1836 o el individuo de la Atalaya o Mesa de Tejina (Tegueste), teniendo más posibilidades, por la presencia de unos elaborados poyetes de piedra donde estaban depositados los cuerpos, los tres individuos del barranco de Amara. En cualquier caso, al contrario de lo que habitualmente se piensa, los hallazgos de momias guanches fueron menos frecuentes y los descubrimientos son casos concretos y puntuales.

Recibido: 14-1-2021; ACEPTAdo: 15-4-2021

151 Tugues, A. y González Díaz, H., com. pers. 